\title{
History and People of Solid-State Diffusion - An Overview
}

\author{
Helmut Mehrer ${ }^{1}$, Graeme E. Murch 2,a \\ ${ }^{1}$ Retired from: Institut für Materialphysik, Universität Münster, Germany \\ Now: Berghof 3, 73635 Obersteinenberg, Germany \\ ${ }^{2}$ Centre for Mass and Thermal Transport in Engineering Materials, School of Engineering, College \\ of Engineering, Science and Environment, The University of Newcastle, Callaghan, NSW 2308, \\ Australia \\ agraeme.murch@newcastle.edu.au
}

\begin{abstract}
In this paper, a brief history of the contributions of many of the major researchers in the field of solid state diffusion is presented starting from 1829 up to the present day. People who are still making significant contributions to the field are mentioned. The authors are well aware that such an attempt is necessarily incomplete and inevitably based on personal knowledge and flavour.
\end{abstract}

\section{What is Diffusion and why is it important?}

Suppose that we put a droplet of ink into a basin of water as indicated by a blue dot in Fig.1. Stirring must be avoided. As time proceeds ink spreads out. Finally, after a long time the basin will be homogeneously coloured by the ink. The underlying process is denoted as diffusion, denominating the transport of ink - in this example - in a liquid. The word diffusion originates from the latin language. The latin word diffundere means 'to spread out'.
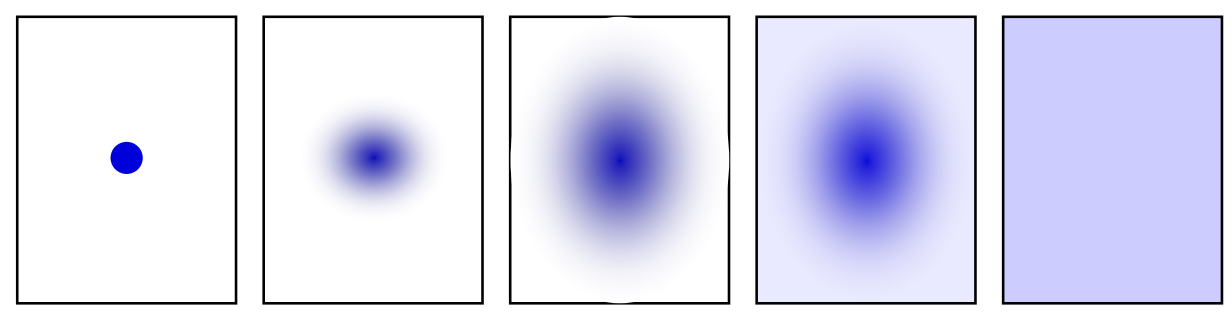

Fig. 1 Illustration of diffusion: motion of ink in water.

On the atomistic scale diffusion is the transport of atoms or molecules in matter from one point to another one by thermal motion, leading to intermixing of the solvent (water) and the solute (ink).. Diffusion phenomena occur in all kinds of matter, i. e., not only in liquids but also in gases, liquids and in solids.

How fast is this process? Diffusion is fastest in gases, where it proceeds at about one centimeter per second. In liquids diffusing material is transported at about one millimeter per second. In solids diffusion transport occurs near the melting temperature at about one micrometer and at half of the melting temperature at about one nanometer per second.

In solids diffusion is relatively slow. For most solids appreciable diffusion takes place well above room temperature. This is also the reason, why diffusion in solids was not detected before the end of the nineteenth century. Before the paradigm 'Corpora non agunt nisi fluida' ('Bodies only react if they are liquid') has been widely accepted by the scientific community.

Nevertheless, already procedures of ancient blacksmiths such as surface hardening of steel swords in coal-fire were in use, which are based on the diffusion of carbon atoms into the crystal lattice of iron. Scientifically, the mentioned paradigm had to be abandoned due to the pioneering work of Sir William Roberts-Austen and of Georg von Hevesy discussed below.

Nowadays, diffusion in solids is an important topic of materials science, solid-state physics, and physical chemistry of solids. Diffusion processes are relevant for the kinetics of many microstructural changes that occur during preparation. processing and heat treatments of solid materials. Examples 
are diffusive phase transformations, nucleation of new phases, precipitation and dissolution of phases, high-temperature creep, homogenization of alloys, and thermal oxidation. Diffusion and electrical conduction in ionic conductors are closely related phenomena.

Important technological applications of diffusion in solids are manifold, e.g., electronic doping of semiconductors during fabrication of microelectronic devices, surface hardening of steels through carburisation or nitridation, diffusion bonding, sintering, and ionic conduction in solid electrolytes for batteries and fuel cells.

\section{Pioneers of Diffusion and Mathematical Description of Diffusion}

The first experimental studies of diffusion were reported by Thomas Graham (1805 - 1869). Graham was a Scottish physical chemist. He was born in Glasgow. Graham's father was a textile manufacturer, and wanted his son to enter into the Church of Scotland. Defying his father's wishes, Graham became a student at the University of Glasgow in 1819. He developed a strong interest in chemistry and became a professor at the Strathclyde University in Glasgow. Later he became professor of chemistry at several colleges including the Royal College of Science and Technology and the University of London. Graham published a textbook Elements of Chemistry, which was for decades the best book in chemistry. He is one of the founders of Physical Chemistry and he discovered the medical method of dialysis. In the year 1854 Graham succeeded Sir John Herschel as Master of the Mint, a reputable office in the government, following the tradition established by Sir Isaac Newton.

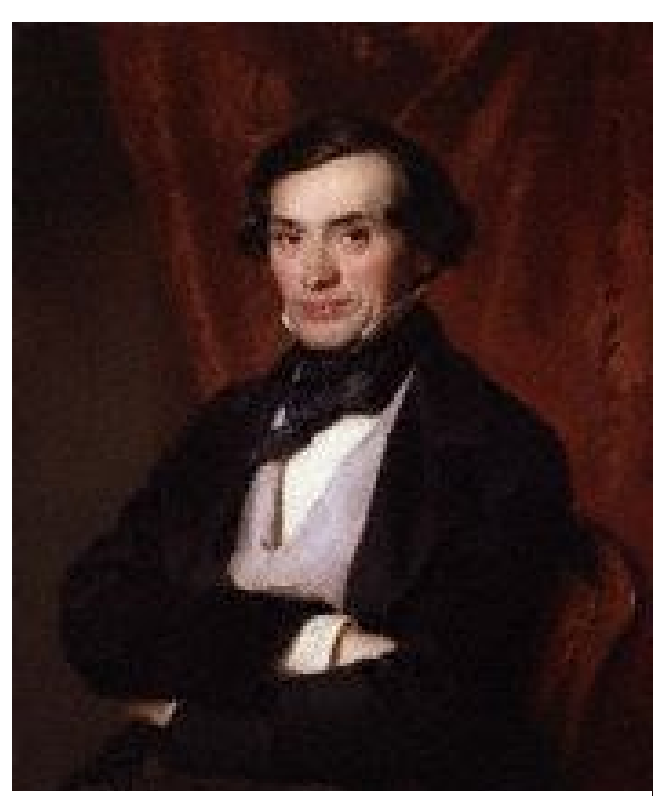

Thomas Graham (1805- 1869)

Graham initiated the quantitative study of diffusion in gases [1, 2]. Graham's law states: Gases with small molecular mass diffuse faster than those with large molecular mass. The velocities of diffusing particles $v_{A}$ and $v_{B}$ are inversely proportional to the square root of molecular masses $M_{A}$ and $M_{B}$ of the gases:

$$
\frac{v_{A}}{v_{B}}=\sqrt{\frac{M_{B}}{M_{A}}}
$$

Eq. (1) is a consequence of the equipartition theorem, which we owe Maxwell, Clausius, and Boltzmann:

$$
\frac{1}{2} M_{A} v_{A}^{2}=\frac{1}{2} M_{B} v_{B}^{2}=k T
$$

In Eq. (2) $k$ denotes the Boltzmann constant and $T$ the absolute temperature. In this way diffusion was connected with the random motion of atoms and molecules. Graham extended his studies to diffusion of salt in liquids [3] and to the uptake of hydrogen in metals. He recognized that diffusion in liquids is at least several thousand times slower than in gases. The notion 'diffusion coefficient' entered science some decades later. 
The next major step in the field came from Adolf Eugen Fick (1829 - 1901). Fick was born 1829 in Kassel, Germany and died in 1901. During secondary schooling Adolf Fick was inspired in particular by the work of Fourier and Poisson. Fick started to study mathematics in Marburg, Germany. On the advice of an elder brother he switched to a study of medicine.

From 1852 to 1868 he stayed at the University of Zürich, Switzerland in various positions. In 1868 Fick became professor in physiology at the University of Würzburg in Germany. Fick is even better known in medicine than in physics. He applied physical laws to studies of living organisms and published textbooks on 'Medical Physics" and on , 'The Anatomy of Sense Organs'.

Graham's work stimulated Fick to develop a mathematical framework to describe diffusion by using the analogy between Fourier's law of thermal conduction [4, 5]. His approach was a phenomenological one.

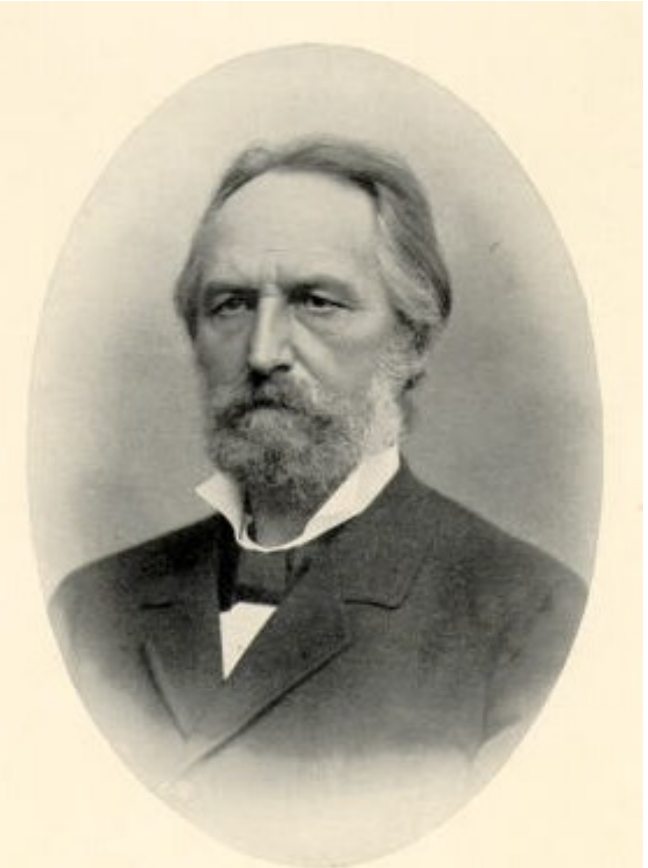

Adolf Fick (1829 - 1901)

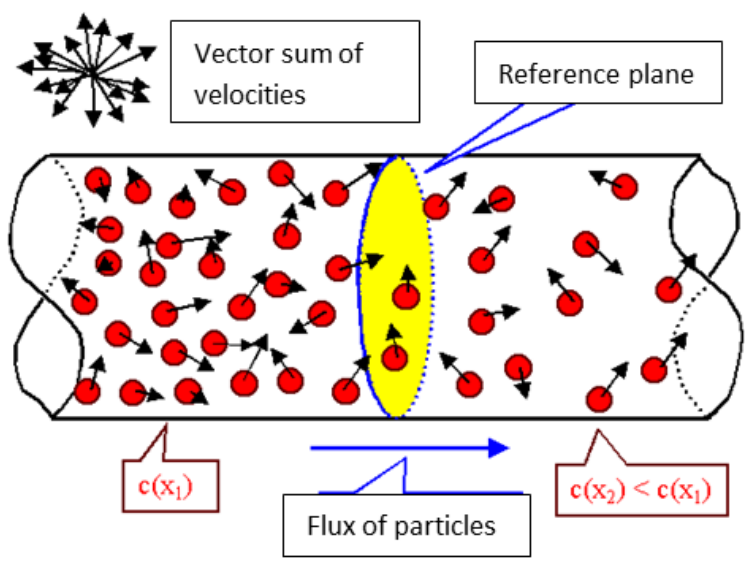

Fig. 2 Illustration of Fick's first law. $C$ denotes the concentration (number density) of diffusing particles, $x$ their position.

In modern language Fick postulated that the flux of diffusing particles $j$ in Fig. 2 (for an isotropic medium) can be written as

$$
j=-D \frac{\partial C}{\partial x}
$$

$C$ denotes the number density (concentration) of diffusing particles and $x$ the position. The negative sign in Eq. (3) indicates that the direction of the diffusion flux is opposite to the concentration gradient. The quantity $D$ is denoted as diffusion coefficient. Diffusion is a process that leads to an equalisation of concentration. The diffusion coefficient has the dimension of length ${ }^{2}$ per time. Its units are $\left[\mathrm{cm}^{2} \mathrm{~s}^{-1}\right]$ or $\left[\mathrm{m}^{2} \mathrm{~s}^{-1}\right]$. Equation (3) is called Fick's first law.

Usually in diffusion processes the number of diffusing particles is conserved. For diffusing species, which obey a conservation law, an equation of continuity can be formulated. Fick's first law and the equation of continuity can be combined to give an equation which is called Fick's second law. If the diffusion coefficient is independent of concentration, Fick's second law simplifies to

$$
\frac{\partial C}{\partial t}=D \Delta C
$$


where $\Delta$ denotes the Laplace operator. This form of Fick's second law is a linear, second order partial differential equation for the concentration $C(x, y, z, t)$.

Fick's major contribution to the field of diffusion was to introduce the notion of a diffusion coefficient. Equation (4) can be used if $D$ is independent of position. An analogous equation is Fourier's law. It holds for the conduction of heat if the thermal conductivity is independent of position. For cases where $D$ is position-dependent we refer the reader to section 9.

If boundary and initial conditions are known, one can strive for solutions of Fick's second law. Experiments are usually designed to satisfy simple initial and boundary conditions. We confine ourselves to the so-called thin-film solution, which is often used in solid-state diffusion experiments. Then the initial condition for the diffusing substance (e.g. a radiotracer) is the following

$$
C(x, 0)=M \delta(x),
$$

where $\delta(x)$ denotes the Dirac delta function. $M$ is a constant. If the diffusant spreads into a halfspace $0<x<\infty$ of a solid body, the solution of Eq. (4) is

$$
C(x, t)=\frac{M}{\sqrt{\pi D t}} \exp \left(-\frac{x^{2}}{4 D t}\right) .
$$

The quantity $2 \sqrt{D t}$ is a characteristic diffusion length, which occurs often in diffusion problems.

\section{Discovery of Solid-state Diffusion by Sir Roberts-Austen}

William Chandler Roberts-Austen (1843 - 1902) became personal assistant to Graham at the Mint in London. After Graham's death he became Graham's successor - a position which he occupied until his death. He was also appointed professor of metallurgy at the Royal School of Mines, and he was knighted by Queen Victoria in 1899. Roberts-Austen was a man of wide interests, with charm and an understanding of people. He became a worldwide authority for properties of metals and alloys and their industrial applications. Austenite, a solution of carbon in iron, is named after him.

Roberts-Austen extended the work of Graham to liquid and solid metals. He studied diffusion of $\mathrm{Au}, \mathrm{Pt}$ and $\mathrm{Rh}$ in liquid lead; of $\mathrm{Au}$ and $\mathrm{Ag}$ and $\mathrm{Pb}$ in liquid tin and of $\mathrm{Au}$ in liquid bismuth. The solidified samples were sectioned and the content of the diffusing species was determined in each section using the precision assaying techniques developed in the Mint. The procedure of

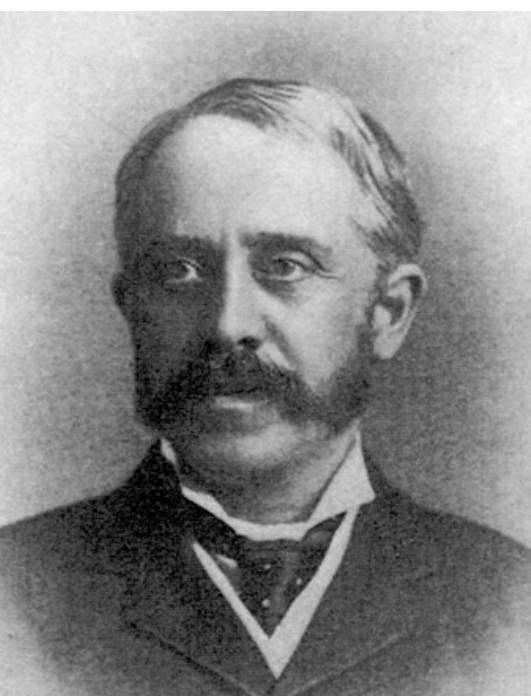

Sir William Chandler RobertsAusten (1843 - 1902) depth profiling is illustrated in Fig. 3. 
$\mathrm{Au}$

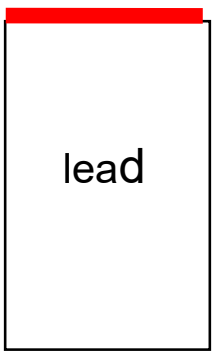

1

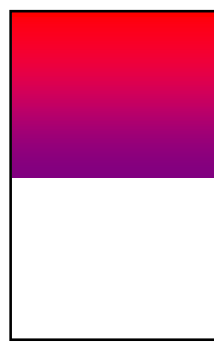

2

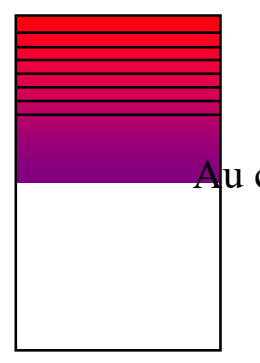

3

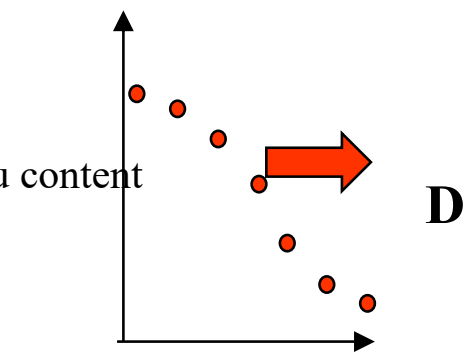

Depth of layer

Fig. 3 Schematic illustration of Roberts-Austen's study of gold diffusion in lead. 1: Deposition of a thin $\mathrm{Au}$ layer on a lead sample. 2: Diffusion anneal at elevated temperature below the melting temperature of lead. 3: Layer sectioning of sample and determination of gold content in each layer.

Roberts-Austen applied this technique also to the study of Au in solid lead [6]. The values of the diffusion coefficients reported by Roberts-Austen are close to the values determined with modern techniques using a radioisotope of gold.

Nowadays we know that the choice of $\mathrm{Au}$ in lead was really fortunate. Diffusion of noble metals in lead is very fast as compared to most other diffusion processes in solids and therefore easier to investigate.

\section{First Measurements of Self-diffusion by Georg von Hevesy}

Self-diffusion is the most basic diffusion process in a solid. The first attempts to study self-diffusion in condensed matter were those of Georg Karl von Hevesy (1885 - 1966). He used a natural radioisotope of lead to study self-diffusion in liquid [7] and solid lead [8]. Von Hevesy was born in Budapest, Austria-Hungary. He studied at the Universities of Budapest, Berlin, and Freiburg.

Von Hevesy had a fascinating scientific career. He did research work in physical chemistry in Zürich, with Fritz Haber in Karlsruhe, with Ernest Rutherford in Manchester, and with Fritz Paneth in Vienna. After World War I he worked from 1920 to 1926 with Niels Bohr at the University of Copenhagen. Together with the Dutch physicist Dirk Coster he detected the element hafnium. From 1926 to 1934 he was professor at the University Freiburg in Germany.

Fleeing from the Nazis in Germany, he moved to the Niels Bohr Institute in Copenhagen and then to Stockholm in Sweden. In 1944 the Swedish Royal Academy awarded him

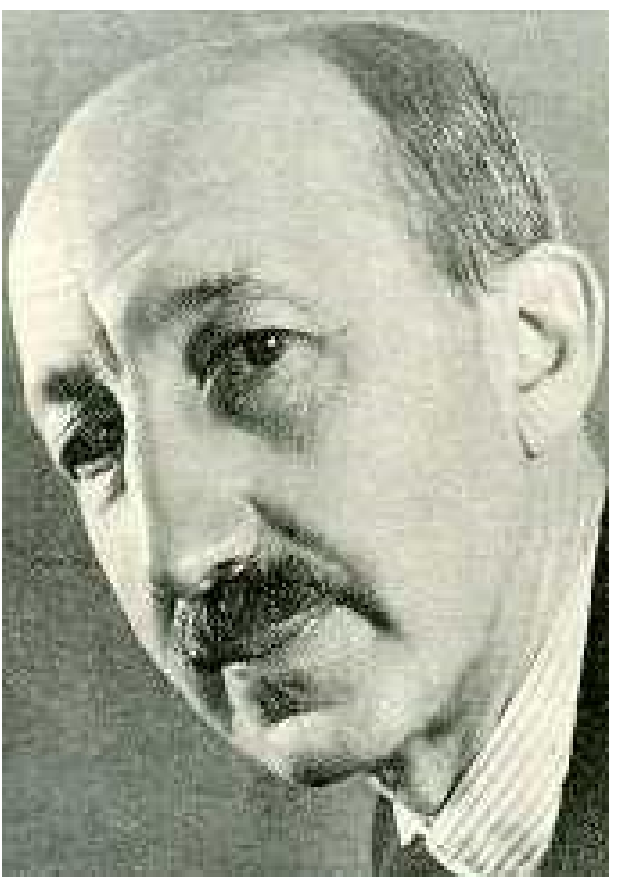

Georg von Hevesy (1885 - 1966) the Nobel Prize in Chemistry of the year 1943 for " ... his work on the use of isotopes as tracers in the study of chemical processes". He became professor in chemistry at the University of Stockholm in 1959. Von Hevesy died in Freiburg, Germany. Wolfgang Seith, who was an associate of von Hevesy in Freiburg, was appointed as professor in physical chemistry at the University of Münster, Germany. An assistant of Seith, Theodor Heumann, became director of the Institut für Materialphysik. His follower from 1984 to 2005 was Helmut Mehrer, one author of the present paper. 

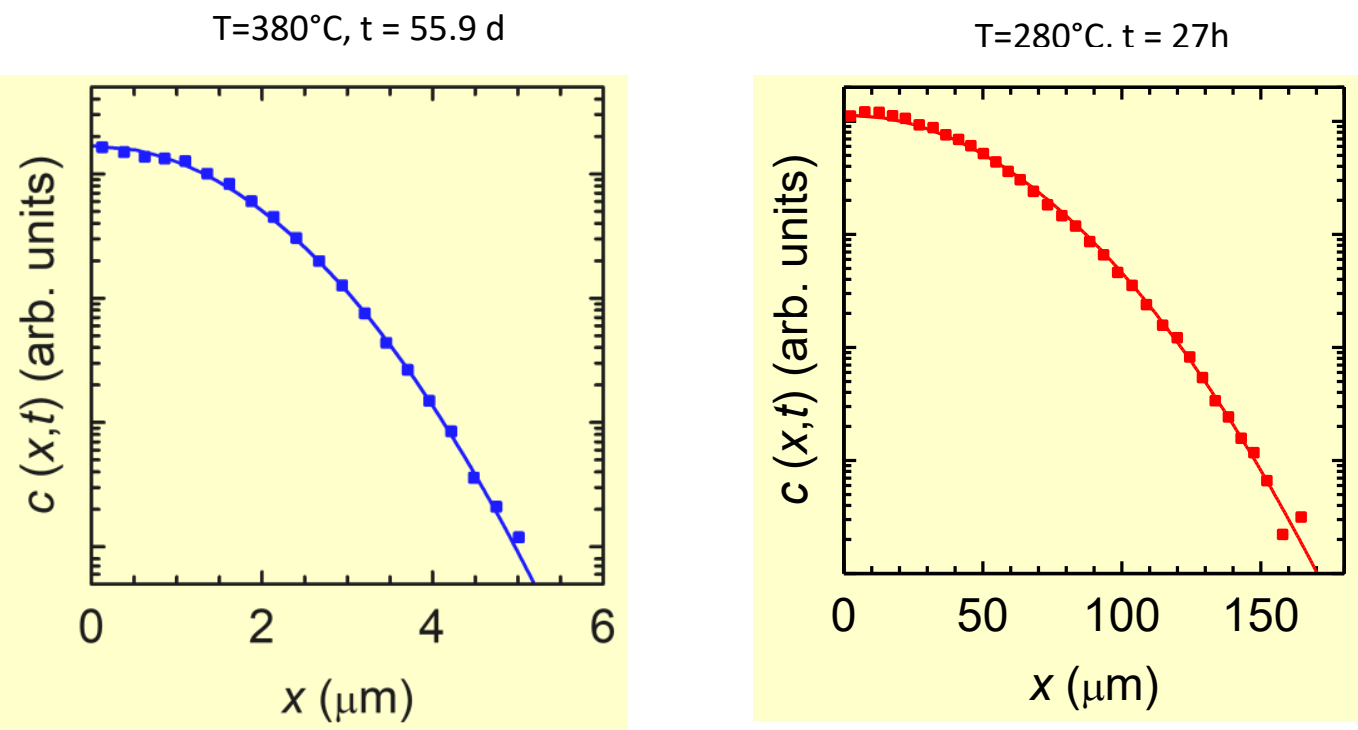

Fig. 4 Penetration profiles of radioisotopes measured by sputter sectioning (left: $\mathrm{Na}^{22}$ in $0.2 \mathrm{Rb}_{2} \mathrm{O} 0.8$ $\mathrm{B}_{2} \mathrm{O}_{3}$ glass) and by grinder sectioning (right: $\mathrm{Rb}^{86}$ in $0.2 \mathrm{Rb}_{2} \mathrm{O} 0.8 \mathrm{~B}_{2} \mathrm{O}_{3}$ glass). The data are fitted by Eq. (6), the thin-film solution of Fick's second law.

\section{Arrhenius Law of Solid-state Diffusion}

The temperature dependence of diffusion and of reaction rates is named after the Swedish scientist Svante August Arrhenius (1859-1927). Arrhenius received his PhD in chemistry at the University of Uppsala in Sweden in 1884, with a thesis about electrolytic dissociation. He was awarded a travel fellowship which enabled him to work with Ostwald in Riga (now Latvia), with Kohlrausch in Würzburg (Germany), Boltzmann in Graz (Austria) and with van't Hoff in Amsterdam (Netherlands). Arrhenius got a chair in chemistry at the University of Stockholm in 1891.

Arrhenius left this position in 1905 to become director of the Nobel Institute of Physical Chemistry. In 1903 he had won the Nobel Prize in chemistry for his '... theory of electrolytic dissociation'. Arrhenius was a many-sided scientist. He also worked in geophysics and he predicted a climate change due to $\mathrm{CO}_{2}$ - emissions already in 1896.

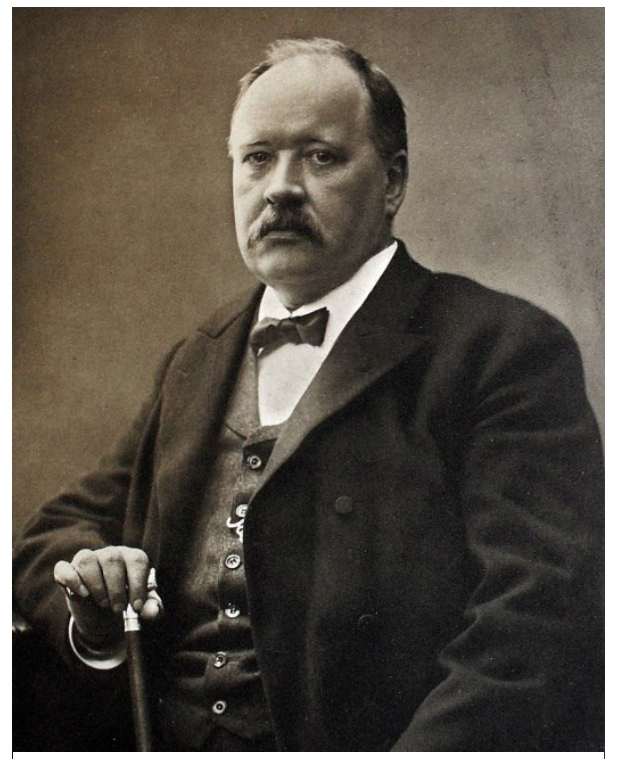

Svante Arrhenius (1859 - 1927)

The suggestion that diffusion in solids obeys an Arrhenius law was made by the American scientists Dushman and Langmuir in 1922 [10]:

$$
D=D_{0} \exp (-Q / k T) \quad .
$$

In Eq. (7) $D$ is the diffusion coefficient, $D_{0}$ is denoted pre-exponential factor and $Q$ activation enthalpy of diffusion. $k$ denotes the Boltzmann constant.

Fig. 5 shows an Arrhenius diagram of self-diffusion for several bcc metals. In an Arrhenius diagram diffusion coefficients are plotted on a logarithmic scale versus the inverse temperature. Then for a constant activation enthalpy the diagram is a straight line. With decreasing temperature the diffusion coefficients decrease several orders of magnitude. In Fig. 5 the temperature scale is normalized with the melting temperature of each metal to permit better comparison of different metals. 


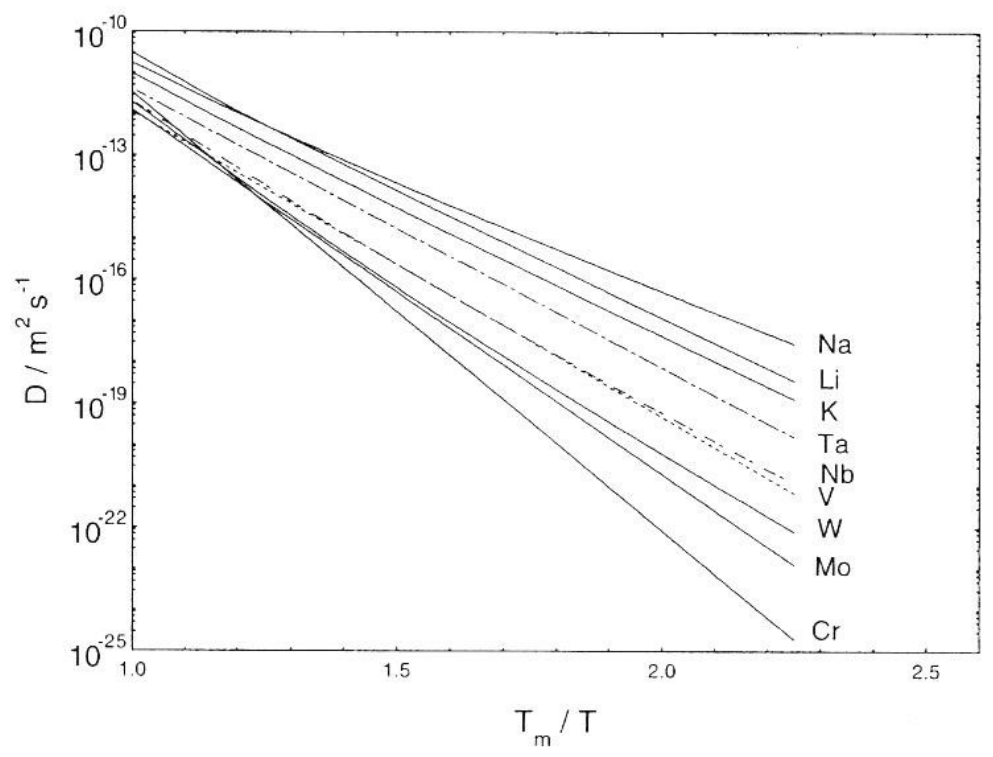

Fig. 5 Arrhenius diagram of bcc metals in a temperature scale normalized with the melting temperature $T_{m}$ of each metal. From [26]

\section{Brownian Motion and the Theory of Einstein and Smoluchowski}

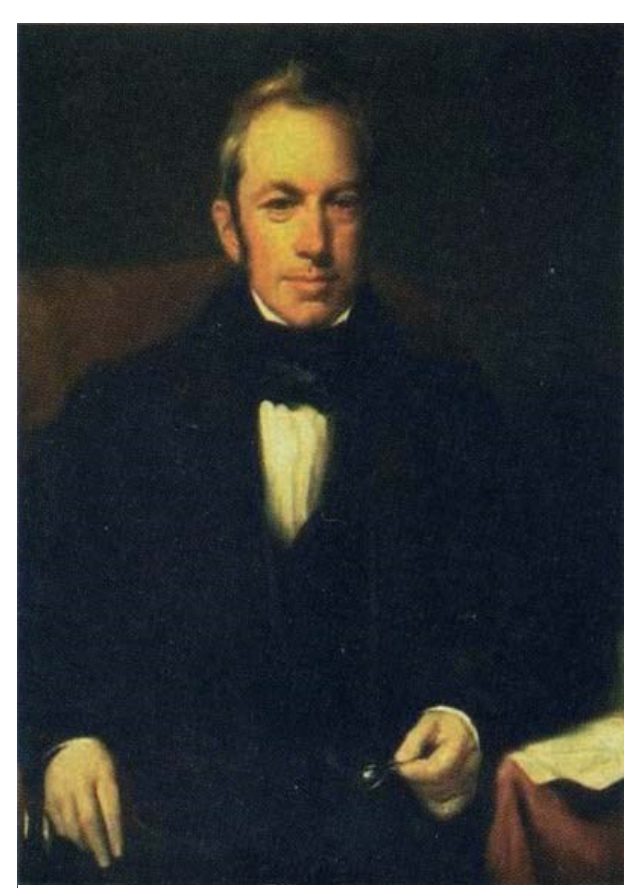

Robert Brown (1773 - 1858).

The phenomenon of irregular motion of small particles has been known since 1827. It had been discovered by the Scottish botanist Robert Brown (1773 - 1858). Brown started to study medicine at the Edinburgh University. At the age of twentyone he enlisted in a newly raised Scottish regiment. His true interests lay not in medicine but in botany. At that time he already had acquired some reputation as a botanist. On a visit to London in 1798 to recruit for his regiment he met the botanist Sir Joseph Banks, president of the Royal Society. Banks recommended Brown to the Admiralty for the post of a naturalist aboard a ship, which was to embark on a voyage to the coasts of Australia.

Brown made extensive plant collections. It took him about five years to classify about 3900 species he had gathered. Almost all were unknown to science. By that time Robert Brown was already a renowned botanist. Brown made several important discoveries. Perhaps the most important one is that plant cells have a nucleus. 1812 Brown became a member of the Royal Society. Much later Charles Darwin referred to him as "... Princeps Botanicorum”.

Robert Brown is best known in science for his description of the random motion of small particles in liquid suspension [9]. Brown investigated in the microscope the way in which pollen acted during impregnation. A plant which he studied was Clarkia Puchella, a wildflower found in the Pacific Northwest of the United States. The pollen of this plant contains granules from five to six micrometres in size. On these granules Brown made his observations. He wrote: "... While examining the shape of these particles immersed in water, I observed many of them very evidently in motion. ... These motions were such as to satisfy me, after frequent repeated observation, that they arose neither from currents in the fluid, nor from its gradual evaporation, but belonged to the particle itself". This inherent, incessant motion is nowadays called Brownian motion in honour of Robert Brown.In the period between 1829 and the beginning of the twentieth century not much progress was made in the 
understanding of Brownian motion. The founders and the developers of the kinetic theory Maxwell, Boltzmann, and Clausius never published anything about Brownian motion. One had to wait for the work of Einstein and Smoluchowski to understand, that the velocity of particles is not a useful quantity to rationalize the motion of particles.

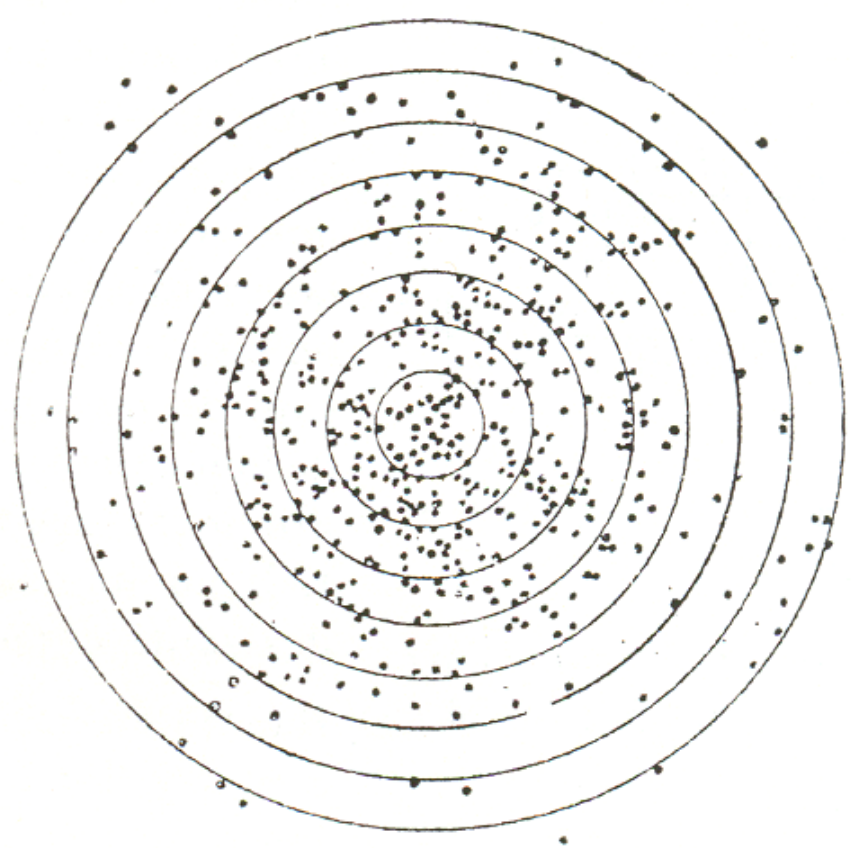

Fig. 6 Illustration of Brownian motion for an ensemble of $N$ particles in two dimensions. Each dot represents the position of one particle after performing a Brownian motion starting at the centre of the circles. From [32].

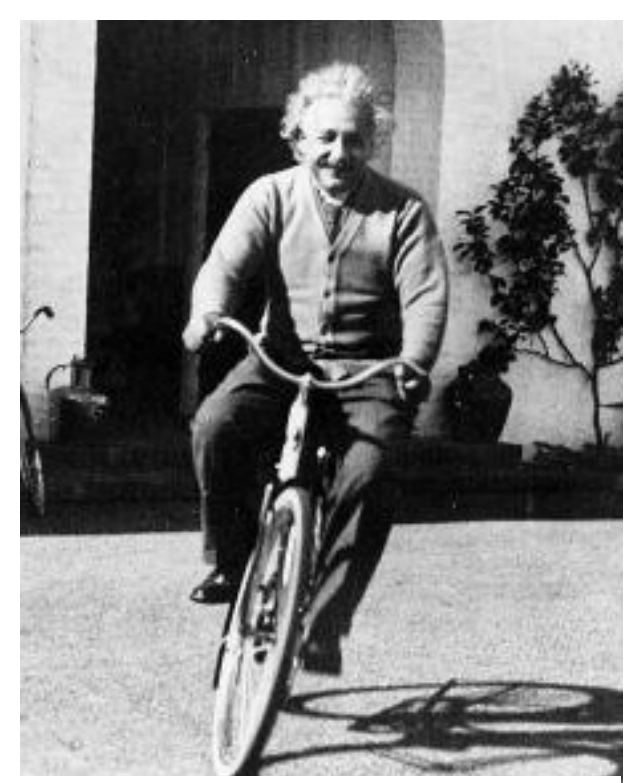

Albert Einstein (1879 - 1955)

Albert Einstein (1879 - 1955), born in Ulm, Germany, is the best known physicist of the twentieth century, perhaps even of all time. In the year 1905, he published four eminent papers that raised him to the rank of a physicist of the highest calibre. One paper was devoted to the explanation of the photo effect, for which he received the Nobel Prize in 1922 for the year 1921. His first paper on Brownian motion and two papers on relativity theory were published in the same year. At that time Einstein was an employee of the Eidgenössische Amt für Geistiges Eigentum in Bern, the capital of Switzerland. He received his doctoral degree one year later. His thesis was on none of the above problems, but was dedicated to the determination of the size of molecules.

His first paper on Brownian motion was entitled: ,Die von der molekularkine-tischen Theorie der Wärme geforderte Bewegung von in ruhenden Flüssigkeiten suspendierten Teilchen '[11]. Einstein was the first scientist to understand, in contrast to many other scientists of the nineteenth century, that the mean square displacement of particles is the basic quantity. He related the mean square displacement of particles to the diffusion coefficient:

$$
<R^{2}(t)>\frac{1}{N} \sum_{1}^{N} R_{i}^{2}=6 D t .
$$

This relation is a cornerstone of diffusion in gases, liquids, and solids. 
The Polish physicist Marian Smoluchowski (1872 - 1917) was born in Vienna, Austria. During Smoluchowski's lifetime Poland was partitioned between Russia, Prussia and Austria.

Smoluchowski entered the University of Vienna and studied physics under Joseph Stephan. He was impressed by the work of Ludwig Boltzmann. In his later life Smoluchowski was called 'der geistige Nachfolger Boltzmanns'. He was appointed professor at Lvov University (now Ukraine) in 1903 and accepted a chair at the Jagellonian University at Cracow in 1913. At this time he was already a physicist of worldwide recognition. Smoluchowski also served as president of the Polish Tatra Society and received the 'Silberne Edelweiss' from the German and Austrian Alpine Society, an award given to distinguished alpinists.

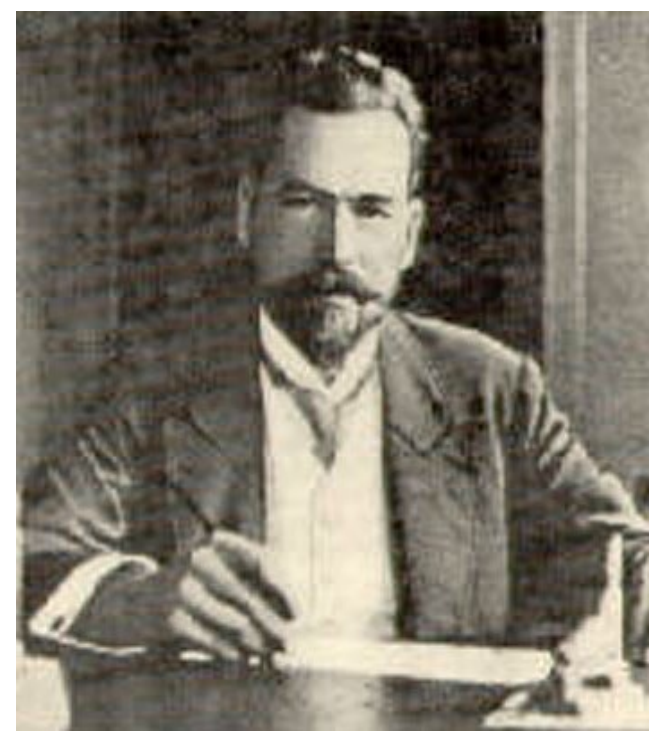

Marian Smoluchowski (1872 - 1917)

Smoluchowski's interest in molecular statis-tics led him already around 1900 to consider Brownian motion. He did publish his results not before 1906 [12] under the impetus of Einstein's paper.

Smoluchowski died as a result of a dysentery epidemic, aggravated by wartime conditions in 1917. Einstein wrote a sympathetic obituary with special reference to Smoluchowski's interest in fluctuations [13].

\section{Atoms are Real - Perrin's Experiments}

The idea that matter consists of atoms was already postulated by Demokrit of Abdera (459 - about 370 before Christ) an ancient Greek philosopher. However, an experimental proof had to wait for more than two millennia. The idea of atoms and molecules took hold of the scientific community since the work of the English scientist John Dalton (1766 - 1844). In addition, the ideas of the Italian scientist Amadeo Avogadro (1776 - 1856), since 1920 a professor in physics at the University of Turin, could be used to construct a table of atomic weights, a central idea of physics and chemistry.

Most scientists were willing to accept atoms as real, because the experimental facts and the kinetic theory of gases provided strong indirect evidence. Yet there were famous sceptics. The most prominent were the German physical chemist at the University of Leipzig Wilhelm Ostwald (1853 1932) and Nobel laureate of 1909 and the Austrian physicist Ernst Mach (1838 - 1916). They accepted that atomic theory was a rational way of summarising experience. However, the lack of direct experimental verification lend them to maintain their scepticism against atomic theory.

The Einstein-Smoluchowski theory of Brownian motion provided ammunition for the atomists. The theory of Brownian motion explains the incessant motion of small particles by fluctuations, which seem to violate the second law of thermodynamics. The question remained, what fluctuates? 
luctuations can be explained on the basis of atoms and molecules that collide with Brownian particles and push them around. The key question that remained was then, what is the experimental evidence that the Einstein-Smoluchowski theory is correct.

The answer had to wait for the studies of the French scientist Jean Baptiste Perrin (1870 - 1942). In order to study the dependence of the mean square displacement on the particle radius, the major challenge was to prepare monodisperse particle suspensions. The experiments of Perrin and his students showed agreement with the Einstein-Smoluchowski theory [14 - 16]. Perrin became an energetic advocate for the reality of atoms, He received in 1926 the Nobel Prize in physics '... for his work on the discontinuous structure of matter'.

Einstein wrote in a letter to Perrin in 1908: "I had assumed that it is impossible to study Brownian motion so precisely; it is very fortunate that you have picked up this subject".

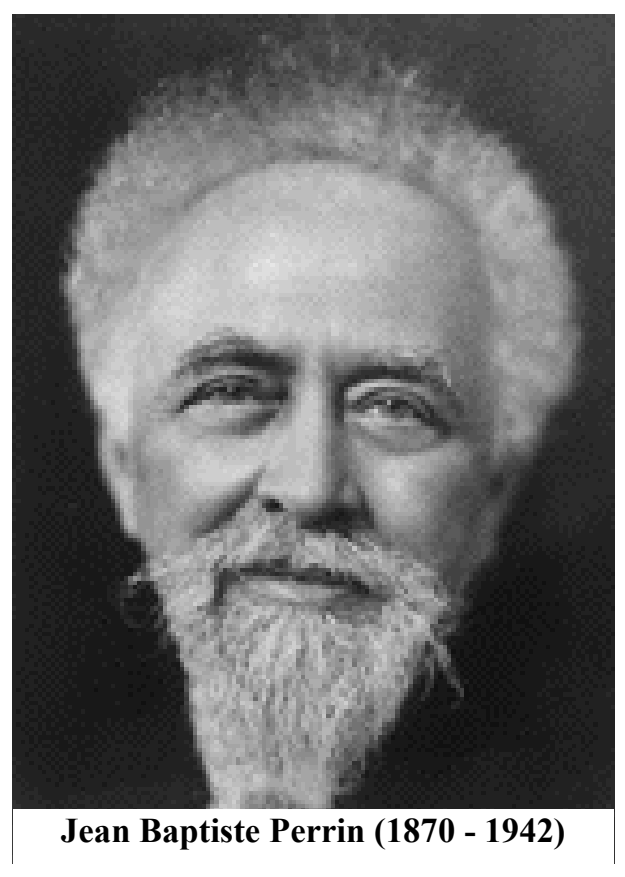

\section{Crystalline Solids and Point Defects as Diffusion Vehicles}

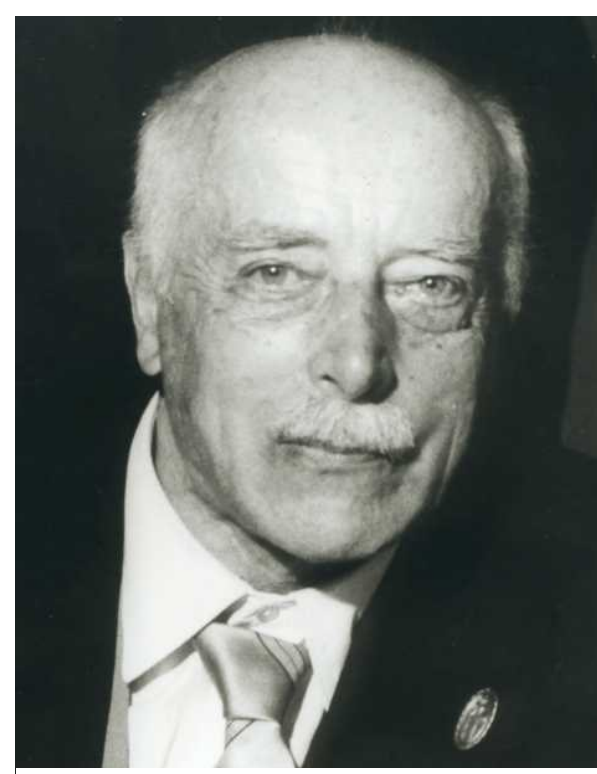

Max von Laue (1879 - 1960)

Max von Laue (1879 - 1960) detected in 1912 together with Friedrich and Knipping the diffraction of X-rays on crystals. His experiments demonstrated that solids usually are threedimensional periodic arrangements of atoms, molecules or ions. Solid-state physics was born.

Max von Laue was professor of theoretical physics in Frankfurt and Berlin. He was awarded already in 1914 with the Nobel Prize in physics.

However, the ideal crystal of Max von Laue is a dead crystal. Diffusion in solids and many other properties of solids require deviations from an ideal structure.

The Russian physicist Jakov Il'ich Frenkel (1894 - 1952) introduced the concept of disorder in solid-state physics. He suggested that thermal agitation causes transitions of atoms or ions from their regular lattice sites to interstitial sites leaving behind vacancies.

This kind of disorder is nowadays called Frenkel-disorder. It consists of an equal number of vacancies and lattice atoms or ions in interstitial sites of the host crystal. Frenkel also worked on plastic deformation and dislocations. 


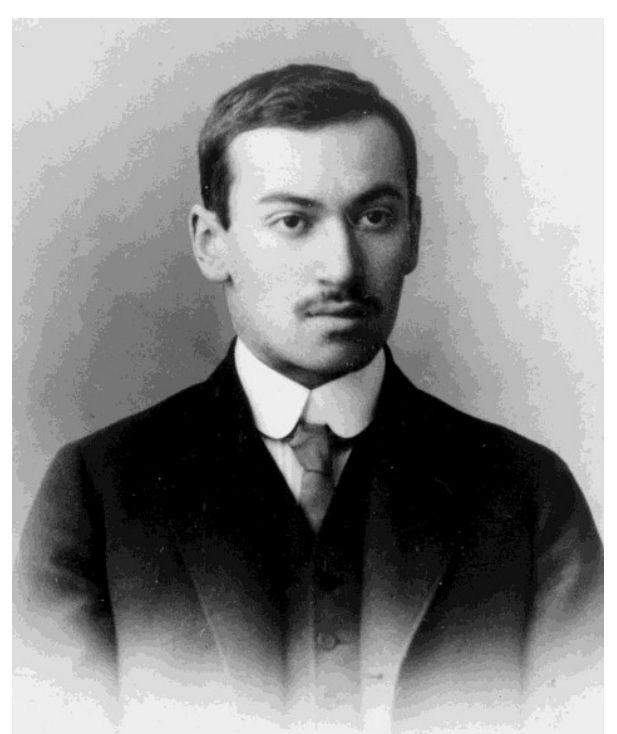

Jakov Il'ich Frenkel (1894 - 1952)

Only a few years later Wagner and Schottky generalised the concept of disorder. They considered vacancies, selfinterstitials, and antisite defects in both sublattices of a binary crystal. Nowadays it is common wisdom that atomic defects are the vehicles of diffusion.

The German physicist Walter Schottky (1886 -1975) taught theoretical physics at the universities Rostock and Würzburg. He worked also in the research laboratories of the

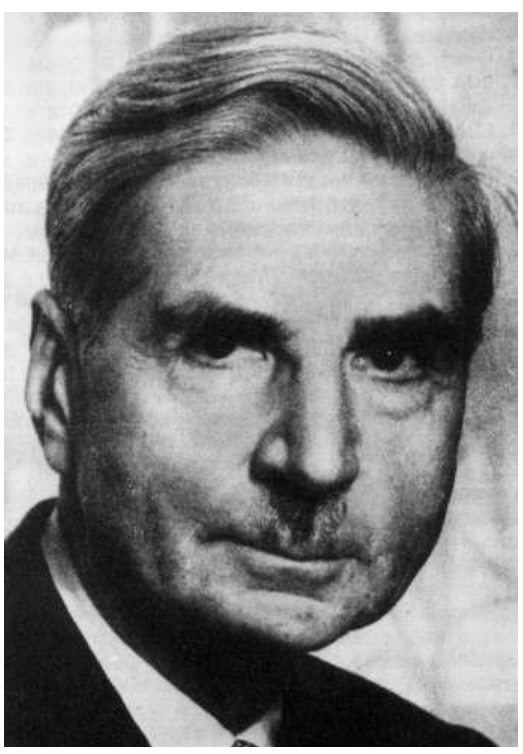

Walter Schottky (1886 - 1975) Siemens Company. He had a

strong influence on the development of telecommunication. His team moved during World War II to the small southern German city of Pretzfeld. In 1946 a Siemens laboratory was installed in the Castle of Pretzfeld. Schottky died in Pretzfeld in 1975. Schottky-diodes and Schottky-contacts are named after him.

Since 1973 the German Physical Society decorates outstanding achievements of young scientist in solid-state physics with the 'Walter Schottky award'. A research facility in semiconductor physics at the Technical University of Munich is named after Schottky.

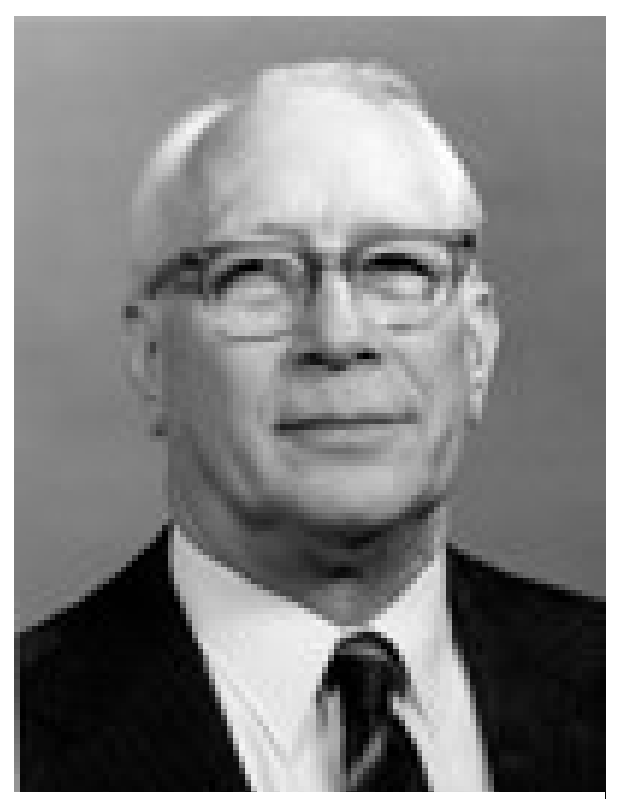

Ernest KIrkendall (1914 - 2005)

A further cornerstone of solid-state diffusion is due to the work of the American Ernest Kirkendall (1914 - 2005). In the nineteen forties it was still a widespread belief that atomic diffusion in metals and alloys takes place via direct exchange or ring mechanisms of atoms. However, this would imply that in binary alloys both components should have the same diffusion coefficient.

Kirkendall and co-workers [18 - 20] studied the interface between diffusion couples of copper and brass, a copper-zinc alloy. The interface between copper and brass was marked by inert molybdenum wires. The wires moved during the annealing treatment as indicated in Fig. 7. The direction of the movement was such that zinc diffusion out of brass was faster than copper diffusion. The movement of inert markers placed at the initial interface of a diffusion couple is called the Kirkendall effect.

It took the scientific world about ten years to be appreciate Kirkendall's discovery. The Kirkendall shift is nowadays taken as strong evidence for a vacancy mechanism in metallic solids.

Kirkendall left science and served from 1947 - 1965 as Secretary of American Institute of Mining, Metallurgical and Petroleum Engineers. He then became a manager of the United Engineering Trustees and concluded his career 1979. 


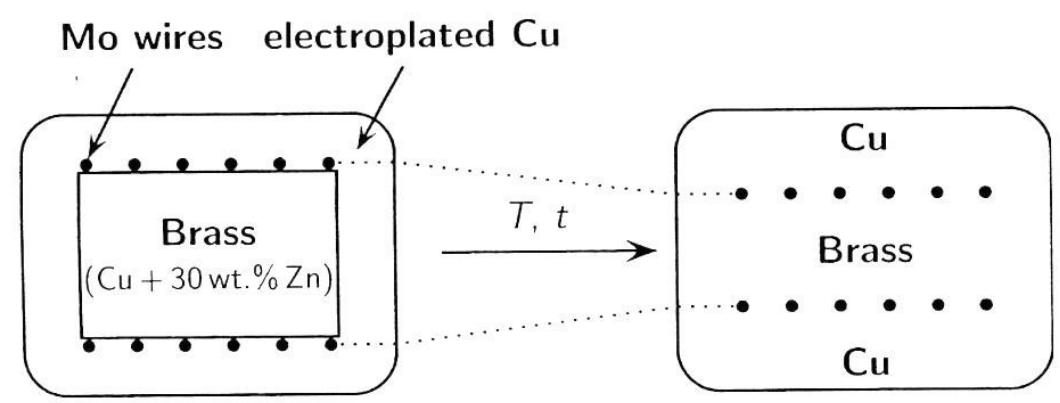

Fig. 7 Schematic illustration of the Kirkendall effect. A diffusion couple composed of pure $\mathrm{Cu}$ and brass $(\mathrm{Cu}-\mathrm{Zn})$ before (left) and after (right) heat treatment is shown. The molybdenum markers placed at the original contact surface moved towards each other, because $\mathrm{Zn}$ atoms diffused faster into brass than $\mathrm{Cu}$ atoms moved inwards.

As knowledge about solids expanded, vacancies were accepted as the major diffusion vehicle in metals and alloys. An atom is said to diffuse by the vacancy mechanism, if it jumps into a neighbouring vacancy as indicated in Fig. 8. Each diffusing atom moves through the crystal by a series of exchanges with vacancies, which from time to time are on its neighbouring site.

In thermal equilibrium the site fraction of vacancies, $C_{V}$, is given by

$$
C_{V}=\exp \left(-G^{F} / k T\right)
$$

where $G^{F}$ is the Gibbs free energy of vacancy formation. It is composed of an enthalpy $H^{F}$ and an entropy $S^{F}$ according to

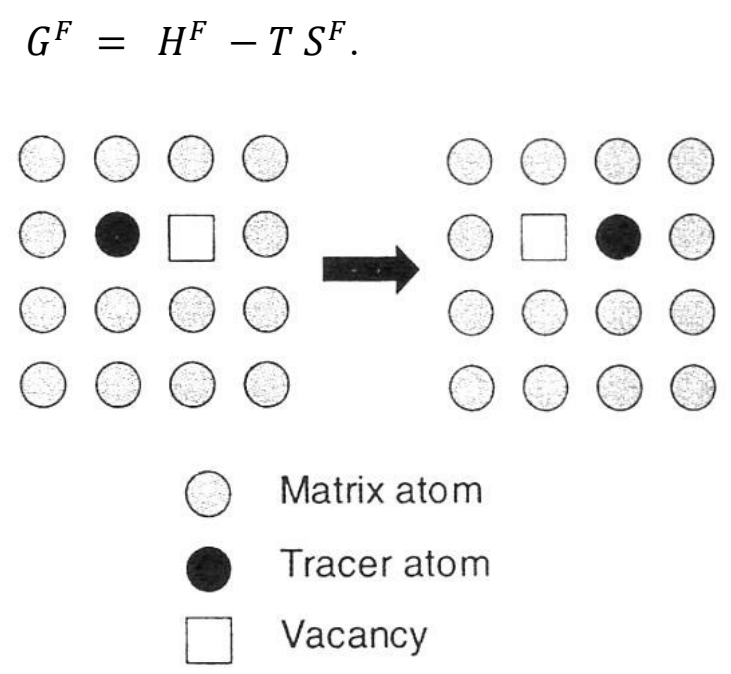

Fig. 8 Vacancy mechanism of atomic diffusion in a crystal. From [26].

\section{Interdiffusion and Boltzmann-Matano Method}

Diffusion processes in alloys with composition dependent diffusion coefficient are of great practical interest. Let us consider a binary diffusion couple, in which the chemical composition varies. Diffusing atoms then experience different chemical environments and have a composition dependent diffusion coefficient. This situation is called interdiffusion or chemical diffusion. Fick's second law then reads

$$
\frac{\partial C}{\partial t}=\frac{\partial}{\partial x}\left[D(C) \frac{\partial C}{\partial x}\right]
$$


We use the symbol $D(C)$ to denote the composition-dependent interdiffusion coefficient. The composition-depth profile in a binary diffusion couple can be measured, e.g., by electron microprobe analysis. A schematic example is shown in Fig. 9.

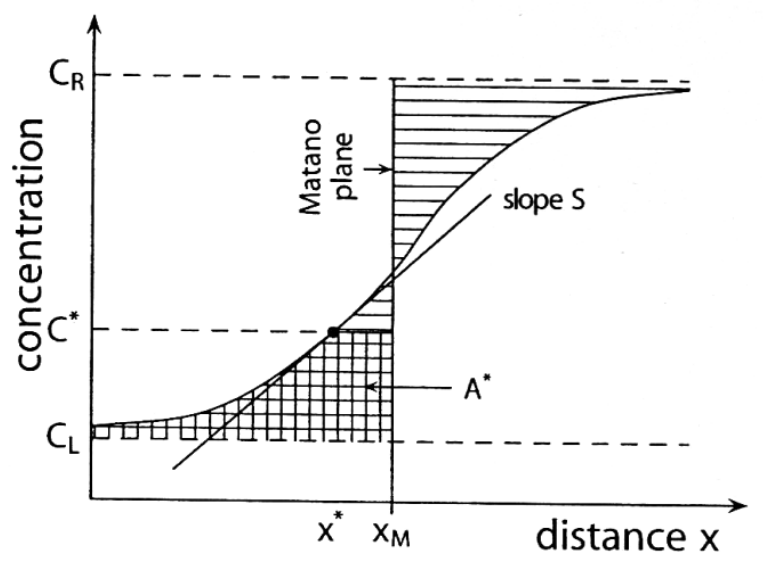

Fig. 9 Interdiffusion profile of a binary diffusion couple and illustration of the Boltzmann-Matano method. From [26].

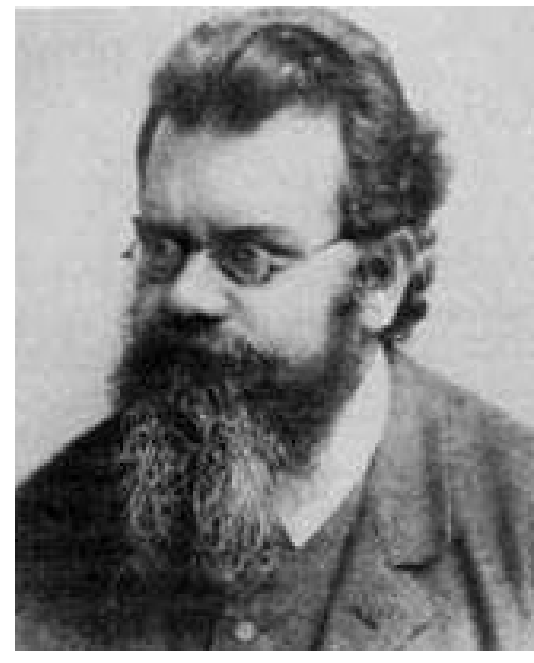

Ludwig Boltzmann (1844 - 1905)

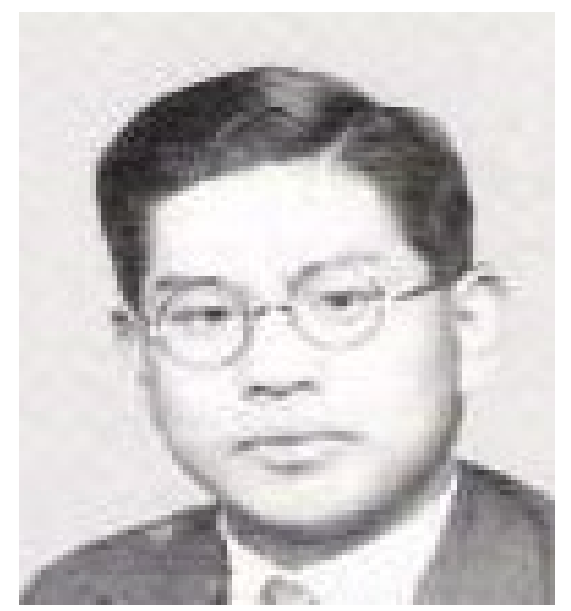

Chujirou Matano (1905 - 1947)
From such a profile the interdiffusion coefficient can be determined by the following procedure:

$D\left(C^{*}\right)=-\frac{1}{2 t} \int_{C_{L}}^{C^{*}}\left(x-x_{M}\right) d C /(d C / d x)_{C^{*}}=-\frac{1}{2 t} \frac{A^{*}}{S}$.

The procedure is illustrated in Fig. 9. At first one determines the Matano plane $x_{M}$. For $x_{M}$ the two horizontally hatched areas are equal. Then one determines the double hatched area $A^{*}$ and the slope $S$. This procedure was proposed by Boltzmann [21] and Matano [22].

Ludwig Boltzmann (1844 - 1905) is a hero of classical physics. $\mathrm{He}$ was born in Linz, Austria, obtained his $\mathrm{PhD}$ from the University in Vienna and became assistant to Joseph Stephan. Boltzmann was professor in Vienna, Graz, Munich and Leipzig. He died in September near Triest. We owe him statistical thermodynamics, Boltzmann equation, Boltzmann distribution and Boltzmann constant. He was also interested in fluid dynamics and in diffusion.

Chujirou Matano (1905 - 1947) graduated in physics at Kyoto University, Japan. He became research associate at Osaka University. He then worked for a big cotton spinning company and wrote a textbook on Physics of Fibers. He died in 1947, when he was professor at Kyushu University. 


\section{Grain-boundary Diffusion}

The fact that grain-boundary diffusion exists had been well documented by autoradiography images around 1950 by Barnes [23]. The ratio between grain-boundary diffusion and lattice diffusion was estimated to be several orders of magnitude. Fisher published a theoretical model of grain-boundary diffusion already in 1951 [24].

David Turnbull (1915 - 2007) was an American chemist in material science and applied physics. He got his $\mathrm{PhD}$ in physical chemistry from the University of Illinois. He joined the General Electric research laboratories and switched in 1962 to Harvard University. Turnbull has merits in nucleation theory, precipitation hardening, and glass formation in undercooled melts. He detected grain-boundary diffusion in silver polycrystals.

The paper of Fisher together with the experimental work of Hoffman and Turnbull [25] initiated an area of quantitative studies of grain-boundary diffusion in solids. Nowadays, grain-boundary diffusion is a transport phenomenon of fundamental interest and of technical importance in polycrystals and in nanomaterials. The various diffusion paths in a solid and the diffusivities of various diffusion processes are illustrated in Figs. 10 and 11.

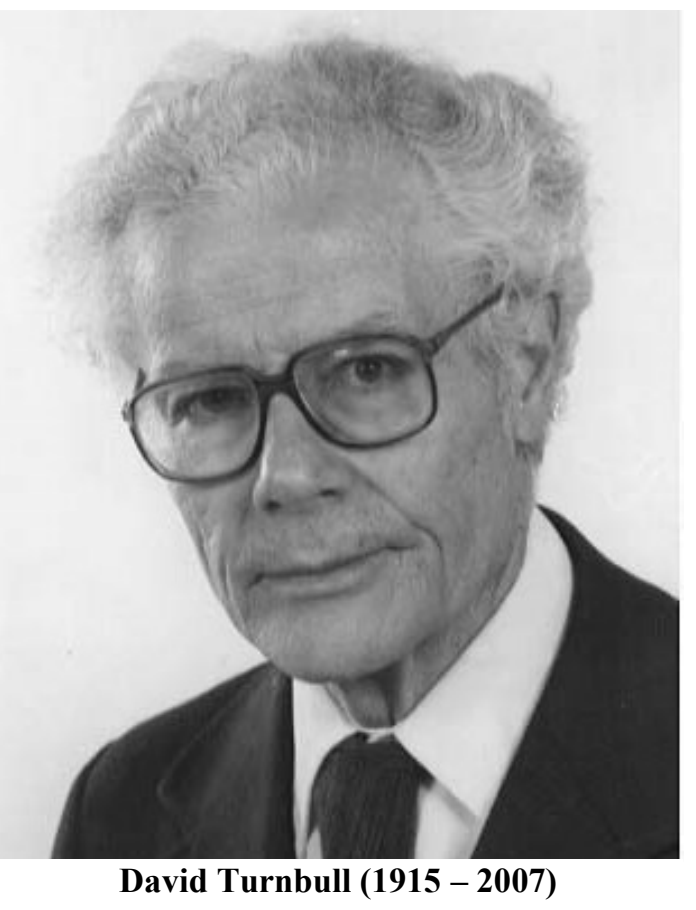

One of the author's colleagues at the University at Münster, Christian Herzig, studied with his students the grain-boundary diffusion in many metals.

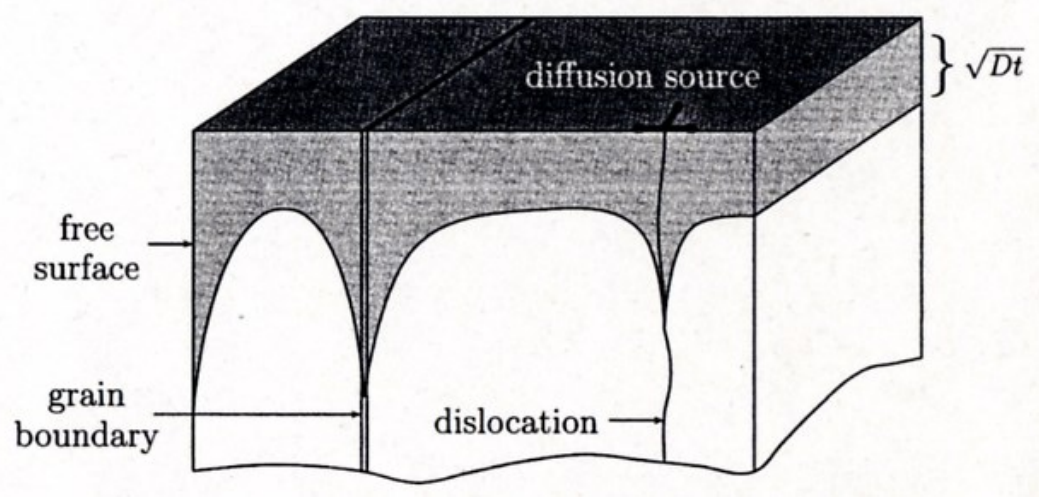

Fig. 10 Illustration of various diffusion processes in a solid: along a surface, along a grain-boundary, along a dislocation line, and in the bulk. From [26]. 


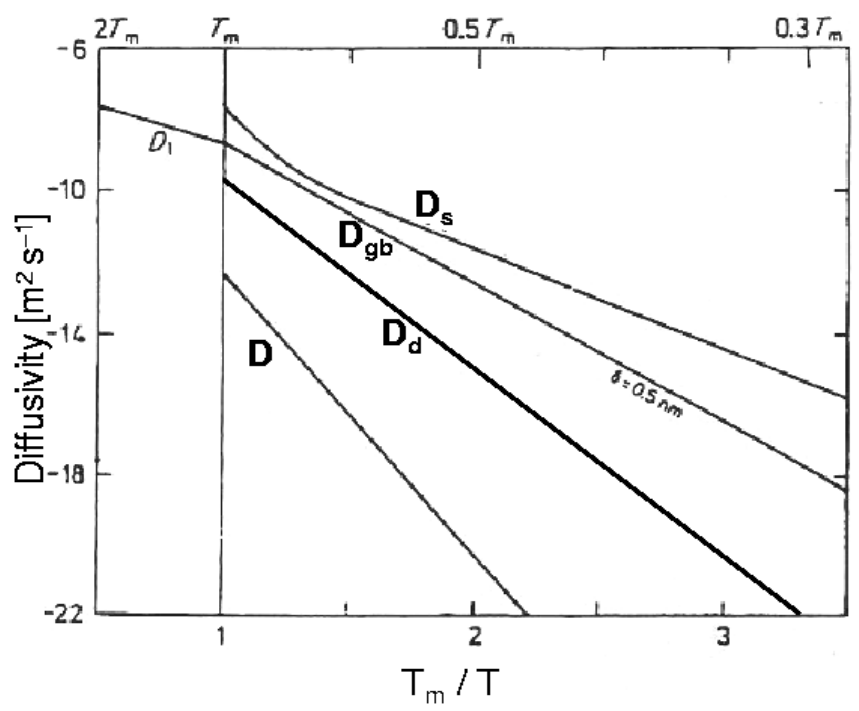

Fig. 11 Comparison of various diffusion processes: $D$ bulk diffusion, $D_{\mathrm{d}}$ diffusion along dislocations, $D_{g b}$ grain-boundary diffusion, $D_{s}$ surface diffusion. From [26].

\section{Correlation Effects in Solid-state Diffusion}

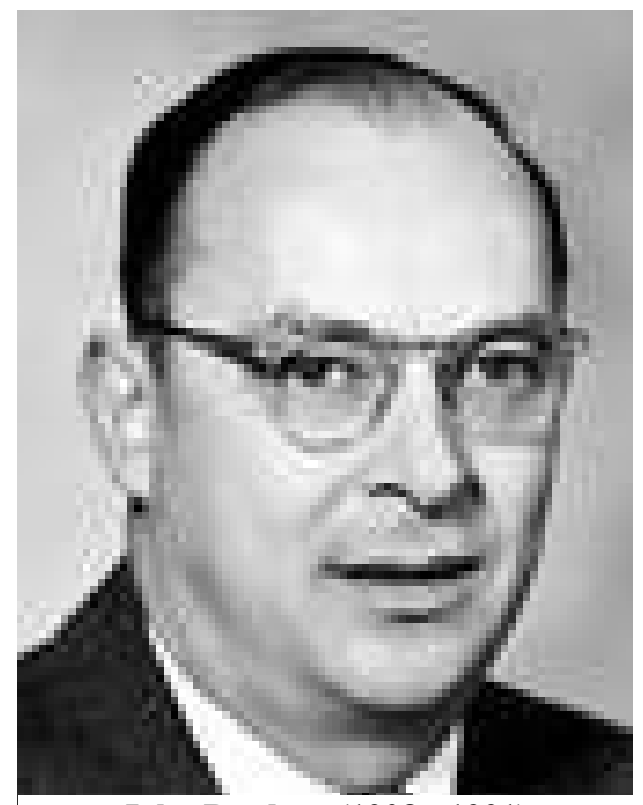

John Bardeen (1908 - 1991)

John Bardeen and Conyers Herring, both from the Bell Telephone Laboratories in New Jersey, USA, recognized in 1951 that diffusion of atoms via a vacancy mechanism is not a random walk but is correlated [27]. After this pioneering work it was appreciated that correlation effects play a role for solidstate diffusion processes, whenever point defects act as diffusion vehicle.

Correlation factors of self-diffusion in cubic lattices are usually numbers smaller than unity and characteristic for a given diffusion mechanism. For a vacancy mechanism in an fcc lattice the correlation factor is 0.781 , for the diamond lattice it is 0.5 . For foreign atom diffusion correlation factors are temperature dependent and contribute to the activation enthalpy of solute diffusion.

We also note that Bardeen is one of the very few scientists, who received the Nobel Prize twice. Schockley, Bardeen, and Brattain were awarded for the development of the transitor in 1956. Bardeen, Cooper, and Schriefer received the Nobel Prize of 1972 for the BCS theory of superconductivity. 
John Manning $(1933$ - 2005) received his $\mathrm{PhD}$ from the University of Illinois, Urbana, USA. He joined in 1958 the metal physics group at the National Bureau of Standards in Washington (NBS/NIST). Later he was the head of this group until his retirement in 1999.

Manning had a strong interest in the Diffusion Kinetics of Atoms in Crystals, as evidenced by the title of his book [28]. The obituary published for Manning by NIST has the following statement: "His papers have explained the significance of the correlation factor and brought about an appreciation of its importance in a variety of diffusion phenomena".

The author of this paper met John Manning on several international conferences. Manning was a great listener and a strong advocate, fair, honest, friendly, courteous and kind.

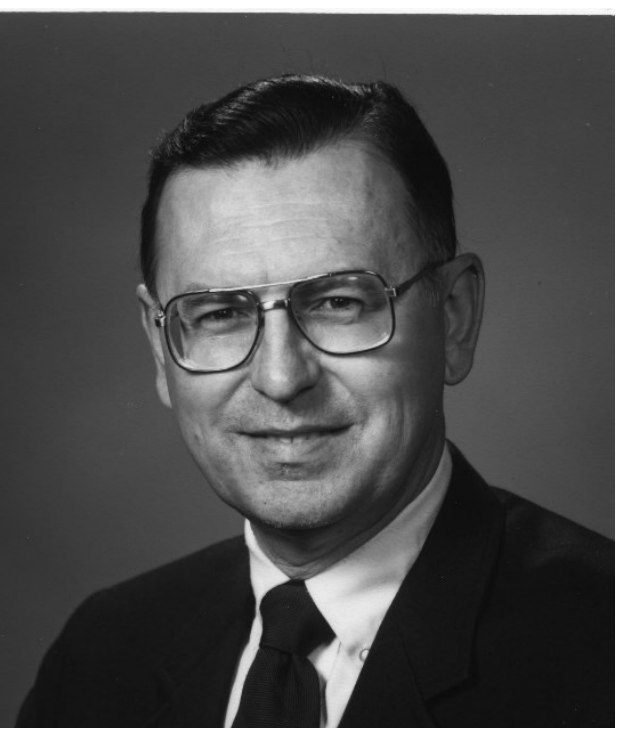

John Manning (1933 - 2005)

\section{Further Scientists in Solid-state Diffusion}

In what follows we mention people, who have made or are still making significant contributions to the field. The authors are well aware that such an attempt is necessarily incomplete and based on personal flavour.

Professor Norman Peterson (1934 - 1985) was a diffusion experimentalist of the highest calibre and a very active and lively person. He was the head of the materials science group at the Argonne National Laboratory, Illinois, USA and later became the head of department at the University of Illinois at Champagne-Urbana. The first author of the present paper visited the Argonne group several times on the occasions of conference trips to the USA.

The Peterson group with the members Steve Rothman, John Mundy, Himanshu Jain and others set new standards for high precision measurements of radiotracer diffusivities in solids. The high precision was also a prerequisite for isotope effect measurements, which contributed substantially to the interpretation of diffusion mechanisms. They also performed studies of grainboundary diffusion in poly- and bi-crystals.

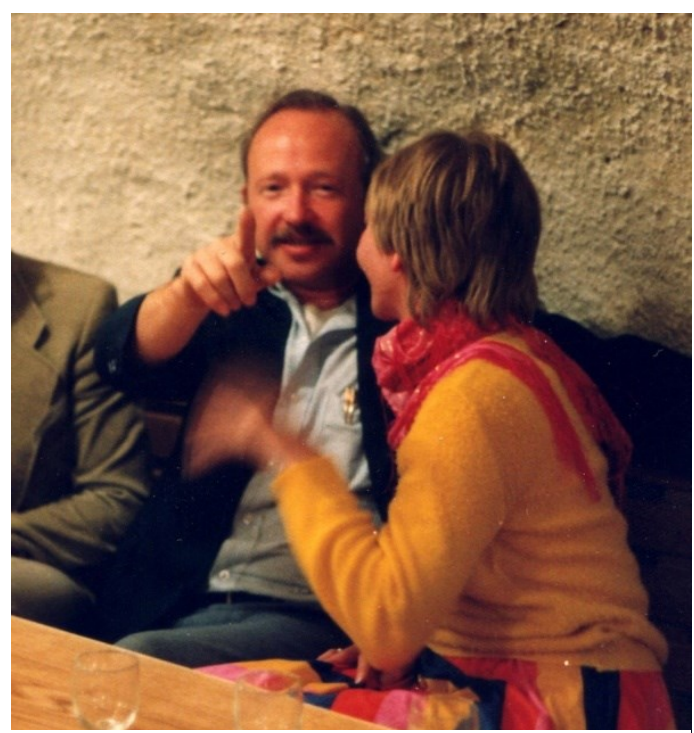

Norman Peterson (1934 - 1985) and Karin Mehrer (wife of Helmut Mehrer)

The first author of this paper and his groups at the University of Stuttgart, Germany, until 1984 and from then to 2005 at the University of Münster, Germany, always kept struggling hard in their own diffusion studies to fulfil the 'Peterson Standards'.

The first author's groups introduced micro-profiling methods such as sputter sectioning to the measurement of diffusion profiles. Sputter sectioning permitted to extend the temperature range of diffusion studies considerably to lower temperatures. An example is shown in Fig.12. 


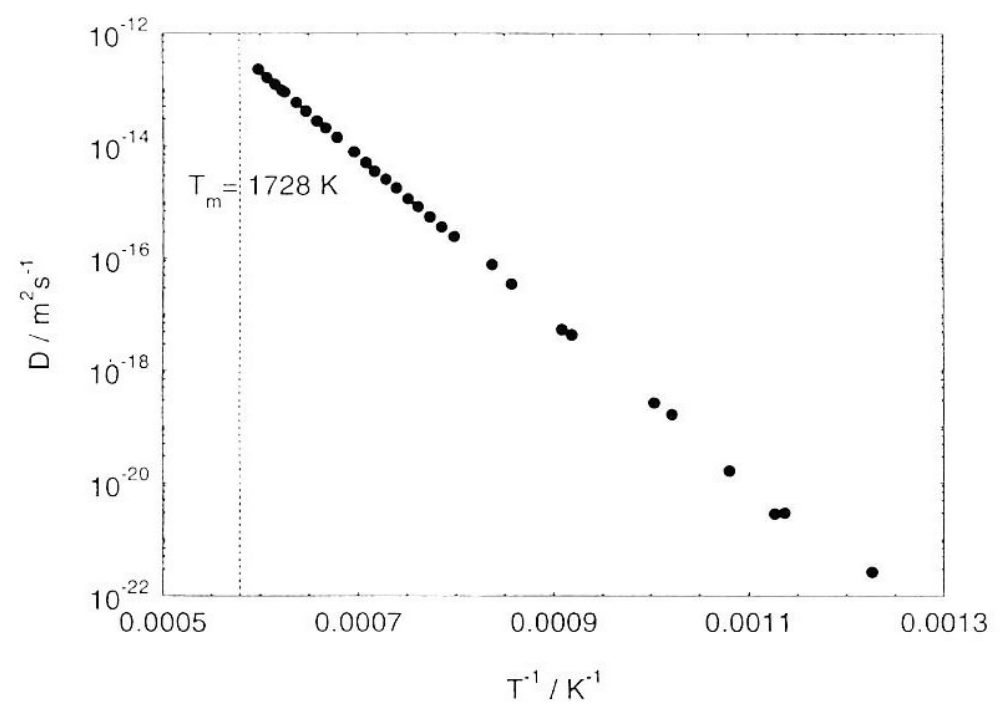

Fig. 12 Self-diffusion of ${ }^{63} \mathrm{Ni}$ in monocrystalline nickel. $\mathrm{T}>1200 \mathrm{~K}$ : data from grinder sectioning; $\mathrm{T}>1200 \mathrm{~K}\left(1 / \mathrm{T}=8.3^{*} 10^{-4}\right)$; data from sputter sectioning $(\mathrm{T}<1200 \mathrm{~K})$. From [26].

The diffusion community owes many enlightening contributions to the British scientist Professor Alan B. Lidiard $(1928$ - 2020). He served at the AERA Technology at Harwell and as professor at the University of Oxford, GB. Lidiard was one of the 'elder statesmen' of diffusion in solids. Together with $A$. R. Allnatt he published a textbook with the title Atomic Transport in Solids [33], which provides a theoretical framework of atomic transport in solids.

In addition, Lidiard is the father of the five-frequency-model [29]. This model provides a theoretical framework for solute and solvent diffusion in dilute alloys and also permits the calculation of correlation effects. Fig. 13 shows an Arrhenius diagram of solute diffusion in silver. The five-frequency model has also been successfully applied to solute diffusion in ionic crystals.

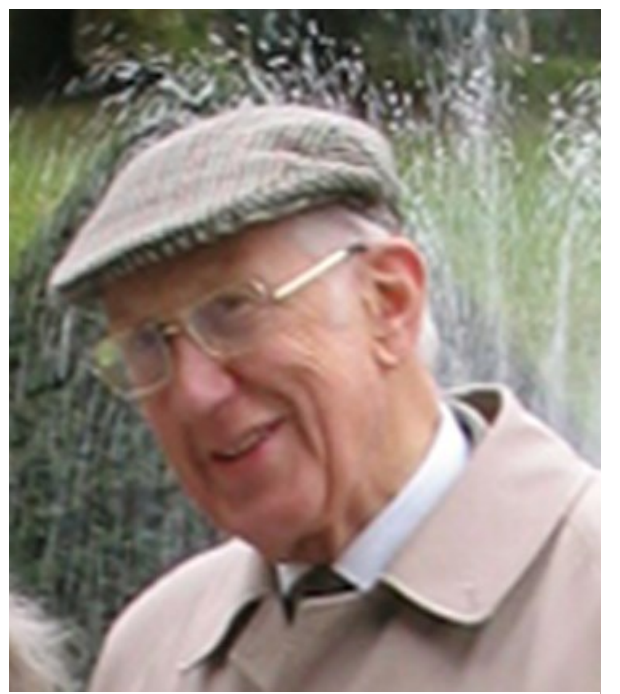

Alan B. Lidiard (1928 - 2020)

As a post-doc (in 1959-61) Alan Allnatt collaborated with Stuart Rice at the University of Chicago on the initial development (Rice-Allnatt equations) of his transport theory for fluids. Fluid state formalisms had a large influence on Allnatt's later solid state work at the University of Manchester (1959-1969). Allnatt derived exact linear response expressions for the Onsager coefficients for models of matter transport by lattice defects in solids governed by a master equation. These were used to develop, by modern cluster theory methods, an analogue, for vacancy transport in ionic crystals, of the Onsager-Fuoss electrolyte theory. 
Later uses, at the University of Western Ontario, began with derivation of highly accurate expressions for the Onsager coefficients for several dilute defect models. Results for the Onsager coefficients of Manning's random alloy model over the whole concentration range were later found to be remarkably accurate. The linear response expressions, recast into Einstein form, were also successfully used for Monte Carlo simulations by the group of the second author of this paper, Graeme Murch, and others. As was mentioned above, collaborations with Alan Lidiard led to a book about statistical theories of matter transport in solids. A career-long interest in thermo-transport, dating from measuring thermo-power of ionic crystals while a graduate student of Patrick Jacobs, has included measurements of the Soret effect in the alkali halides, and an attempt at a theory of the 'heat of transport for a single defect jump'.

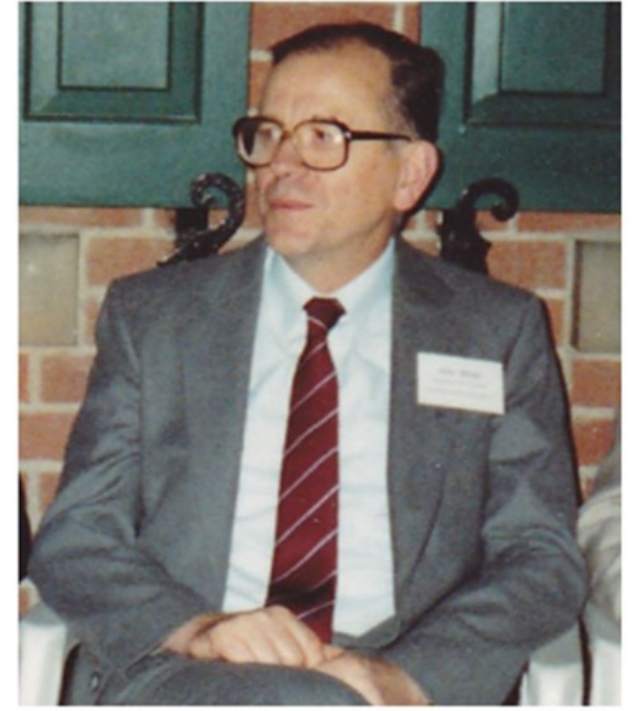

Alan R Allnatt

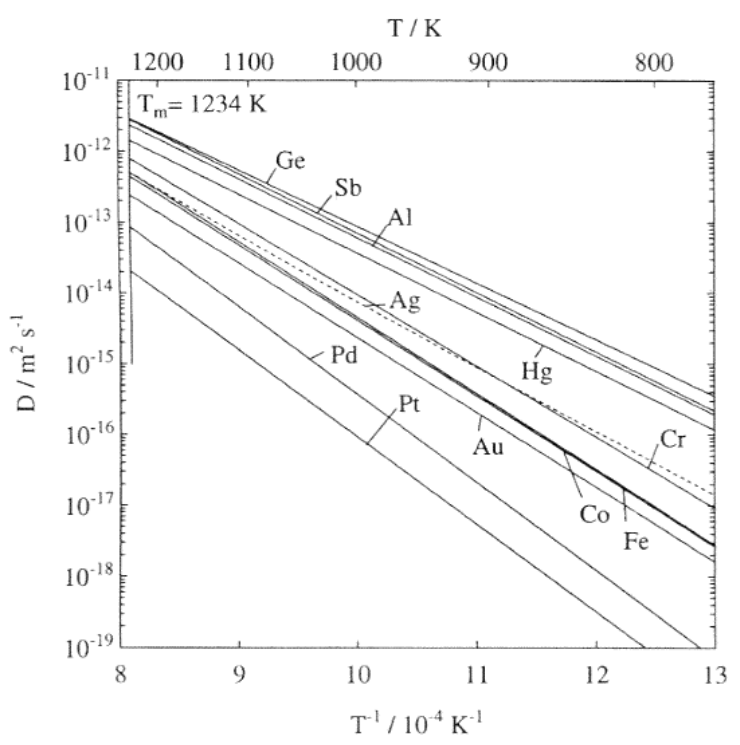

Fig. 13 Arrhenius diagram for diffusion of various solutes in silver. From [26]. 


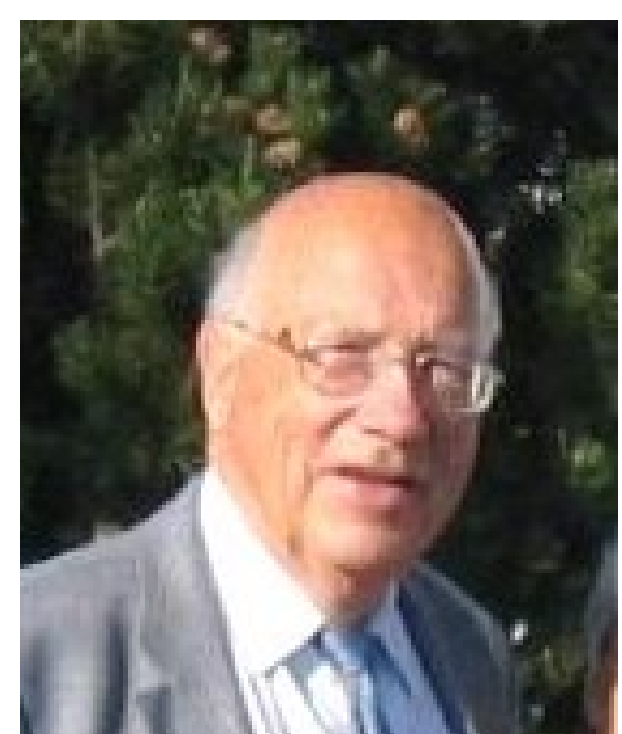

Alfred Seeger (1927 - 2015)

Professor Alfred Seeger (1927 - 2015), professor at the University of Stuttgart and director of the Max-Planck-Institut für Metallforschung (now Max-Planck-Institut für Intelligente Systeme) in Stuttgart, Germany was an expert of high calibre for the science of defects in solids. His fields of interest included point defects such as vacancies, divacancies, self-interstitials, dislocations, and grain-boundaries.

Self-diffusion in metals is mediated by vacancy-type defects and often has also a contribution of divacancies. From a careful analysis of self-diffusion data reliable values of vacancy and divacancy properties could be deduced.

The first author of the present paper performed his research both for the $\mathrm{PhD}$ thesis and for the habilitation thesis in the field of point-defect diffusion in metals in Seeger's group. His interest in diffusion got enhanced during his membership in this group.

Professor Ulrich Gösele (1948 - 2009) got his $\mathrm{PhD}$ at the University of Stuttgart, Germany, for a thesis, which he performed in the group of Seeger at the Max-Planck-Institut für Metallforschung. After being a visiting scientist in South Africa and at the IBM research laboratories in Yorktown Heights, USA, Ulrich Gösele got the habilitation for his thesis titled 'Reaktionskinetik und Diffusion in kondensierten Systemen' (Reaction kinetics and diffusion in condensed systems) at the University of Stuttgart, Germany. In 1985 Ulrich Gösele became full professor at the Duke University in North Carolina, USA. In 1995 he returned to Germany and took the position of the director of the Max Planck Institut für Mikrostrukturphysik in Halle, Germany.

Ulrich Gösele was a many-sided and productive scientist. He is author and co-author of more than 700 journal papers and book chapters. He was interested in many topics of semiconductor

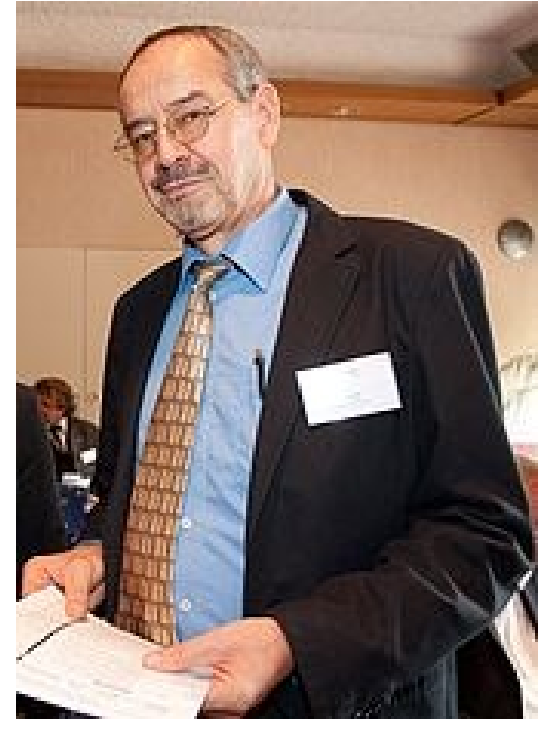

Ulrich Gösele (1949 - 2009) physics and techniques, in solid nano-structures, and also in diffusion and defects in elemental and compound semiconductors. 
Professor Alan D. Le Claire worked at the UKAEA in the UK. Later he was a Professor at the Oxford Research Unit of the Open University, UK. Le Claire contributed three chapters to the data collection Diffusion in Metals and Alloys [34] edited by Helmut Mehrer. One chapter is Diffusion of $C, N$, and $O$ in metals, a second chapter is on Diffusion in Dislocations, and a third chapter together with G. Neumann devoted to Diffusion of Impurities in Solid Metallic Elements.

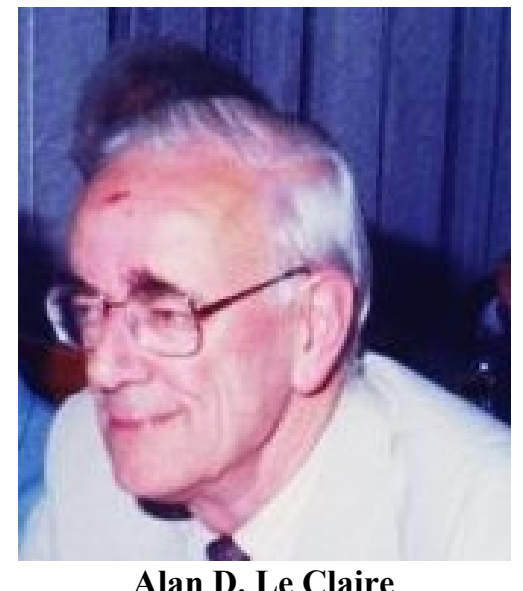

Alan D. Le Claire

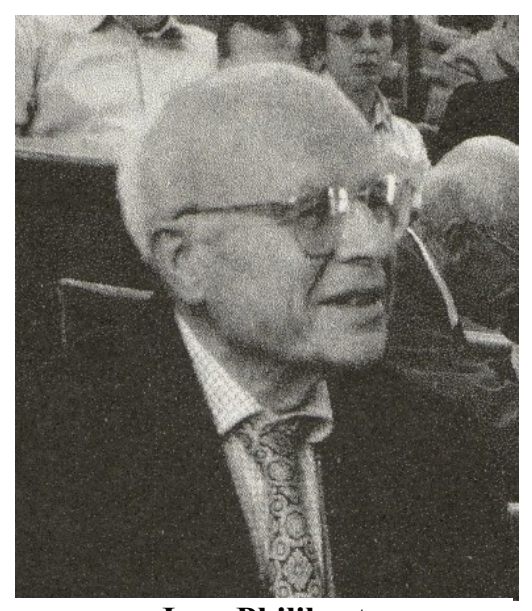

Jean Philibert

Professor Jean Philibert, a retired professor of the University Paris-Sud, France, is a highly respected senior scientist of the international diffusion community. Graduate students in materials science and scientists in industrial laboratories benefit from his textbook mentioned also in Section 14. The first author of this paper often consulted Philibert's book and enjoyed his wellrounded contributions to discussions during diffusion conferences.

Professor Graeme Murch was a scientific member of the materials science group at the Argonne National Laboratory, Illinois, USA before he became the head of a theoretical diffusion group at the University of Newcastle, Australia. Graeme Murch is an expert on computer modelling of diffusion (Monte Carlo and molecular dynamics) and has a profound knowledge of irreversible thermodynamics over a very wide range of situations, from nonstoichiometric compounds, intermetallics, grain boundaries, dislocation pipes, liquid alloys, high entropy alloys, segregation, ionic conductivity and thermal transport. He has written some 460 papers, edited about 40 books on diffusion and about 20 book chapters including one on interdiffusion to a data-collection edited by the first author of this paper [34].

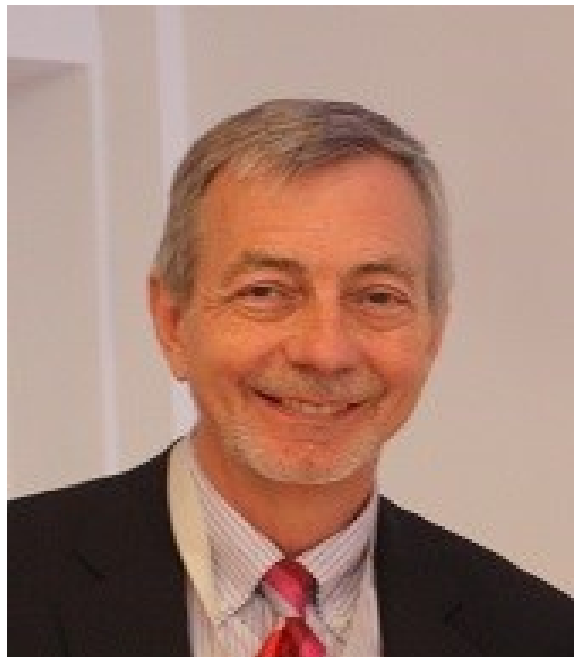

Graeme Murch

Graeme Murch has been the editor-in-chief of the international journals Defect and Diffusion Forum and Diffusion Foundations for many years. These journals are important platforms of the solid-state diffusion community. The proceedings of many international diffusion conferences such as DSL and DIMAT have been published in these journals. 
Professor Irina Belova is a joint director (shared with Professor Graeme Murch) of the theoretical diffusion group at the University of Newcastle, Australia. Irina has a strong background in applied mathematics. She has succeeded in making powerful and impactful contributions to the area of diffusion theory of atoms and heat in solids. In the area of mass and heat diffusion in materials she has published some 320 journal papers and 20 book chapters. These papers and chapters have covered a very wide range of diffusion situations, from diffusion in intermetallic compounds, grainboundary diffusion, ionic conductivity, diffusion in high entropy alloys, diffusion in multi-component alloys, segregation of components and also diffusion in liquid alloys. Her research work covered work on diffusion-related phenomena, especially in porous metals.

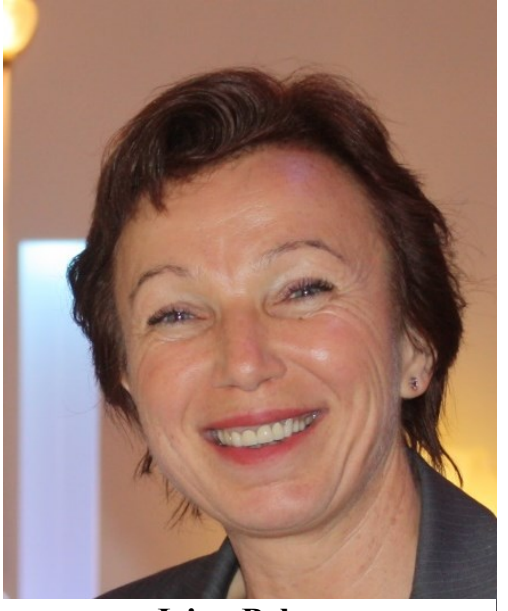

Irina Belova

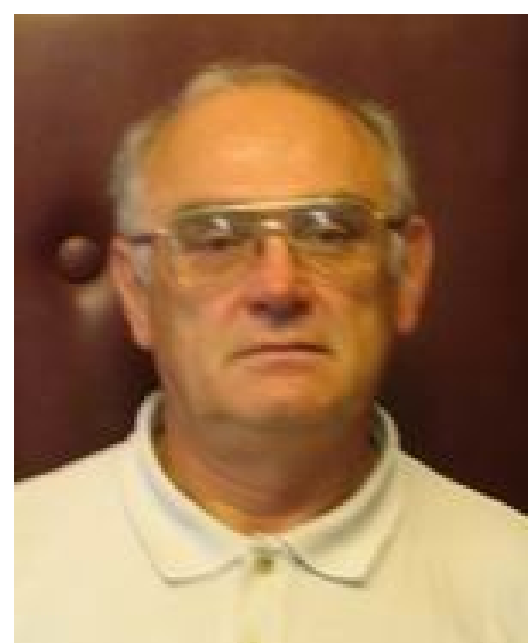

Deszoe Beke

Professor Deszoe Beke, former head of the Solid State Physics Department at the University of Debrecen, Hungary, and his group contributed and still contribute to the field of diffusion in solids. In 1998 Deszoe Beke edited a data collection with the title Diffusion in Semiconductors and Non-metallic Solids [35]. Deszoe Beke organised several inter-national conferences. The first author of this paper has a very good remembrance to the conference DIMETA-82, which took place at Lake Balaton in Hungary. This conference was the first occasion when diffusion experts from both sides of the 'iron curtain' could exchange experiences and ideas. This conference was the starting ignition for a series of international diffusion conferences. Another one, DIMETA-88, was once more organized by Deszoe Beke and his group at Lake Balaton in 1988.

The focus of the two conferences in Hungary was mainly on metals and alloys. In the following conferences the focus was extended to all kind of solid materials and the conference title changed to DIMAT. Up to now DIMAT conferences were organised at the following places: Kyoto, Japan 1992, Münster, Germany 1996, Paris, France 2000, Cracow, Poland 2004, Lanzarote, Spain 2008, Dijon, France in 2011, Münster, Germany 2014, and Haifa, Israel 2017.

The next conference of the DIMAT series is planned to take place in Debrecen, Hungary. DIMAT-21 shall be organized by Zoltan Erdely. Zoltan Erdeliy is the successor of Deszoe Beke in the Solid State Physics Department of the University of Debrecen, Hungary.

The Russian scientist Professor Boris Bokstein, head of the thermodynamics and physical chemistry group of the Moscow Institute of Steels and Alloys (MISIS) organised stimulating international meetings on special topics of solid-state diffusion. These meetings focussed mainly on thermodynamics of grainboundary properties, grain-boundary diffusion of solutes, and segregation of solutes into grain-boundaries.

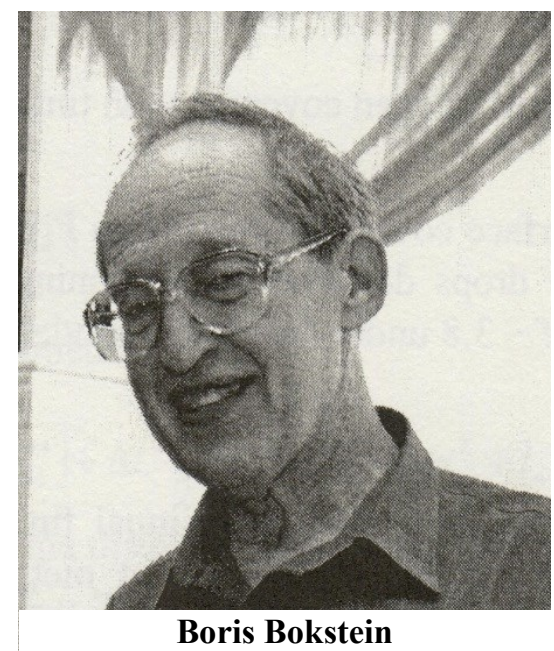

Boris Bokstein 


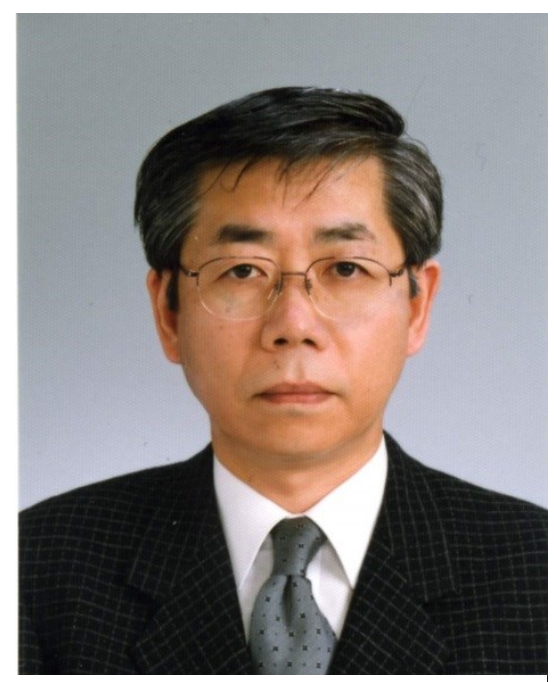

Hideo Nakajima

Professor Hideo Nakajlma got his PhD from the Tohoku University, Japan in 1978. After spending about two years at the Rensselaer Polytechnic Institute, USA, he became Assistant Professor at the Tohoku University in Sendai. He spent about half a year at the Chalk River Nuclear Laboratories, Canada. In 1992 he became Professor at the Faculty of Engineering at the Iwate University in Morioka. He spent again a few months at the Chalk River Nuclear Laboratories. Then he became Professor at the Institute of Scientific and Industrial Research in Osaka. From 2004 to 2008 he served as professor at the Gyeongsang National University in South Korea. Nakajima and his group studied diffusion in alloys, intermetallic compounds, solute diffusion in zirconium, and diffusion in quasicrystals. He was also interested in magnetism, superconductivity and irradiation effects in nuclear fusion materials. He also published a book on Porous Materials.

Together with Professor Koiwa from Kyoto University, Nakajima was co-organiser of the first DIMAT conference, which took place in Kyoto in 1992. The first author of the present paper has a good remembrance of this conference. As result of a discussion of the scientific committee during the conference in Kyoto the Münster group was asked to organise DIMAT-96, which took place in 1996 in Nordkirchen near Münster.

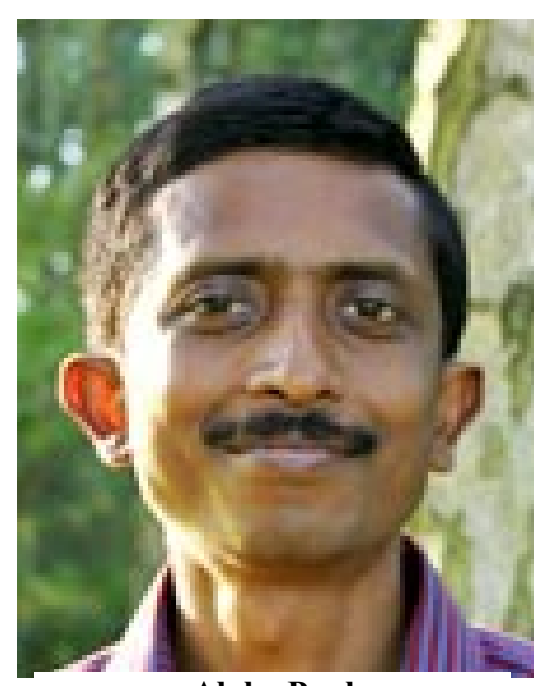

Aloke Paul

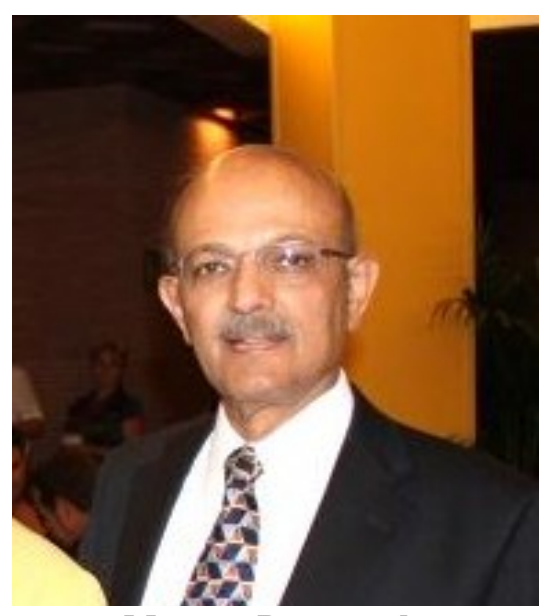

Myssore Dayananda
Professor Aloke Paul is professor at the Indian Institute of Science in Bangalore. His focus is on growth of intermetallic compounds by interdiffusion, diffusion mechanisms in intermetallic compounds, phenomenological theories in binary and multi-component alloys, interdiffusion, and Kirkendall effect. Together with PD Sergiy Divinski from Münster, Germany and two co-authors from Finland, Aloke Paul published a textbook with the title Thermodynamics, Diffusion and the Kirkendall Effect in Solids [40].

Professor Mysore Dayananda is professor emeritus of Materials Engineering of the Purdue University in West Lafayette, Indiana, USA. He obtained his PhD from the Indian Institute of Science in Bangalore and joined the Purdue faculty in 1966.

Mysore Dayananda has held Visiting Professorships at Münster University in Germany (1980) and at the Indian Institute of Science (1992) in Bangalore, India.

Mysore Dayananda is expert for diffusion in alloys with more than two components. His diffusion research in multicomponent systems includes both theoretical and experimental studies of intrinsic diffusion and interdiffusion in metallic alloys, intermetallic phases, and silicides. A free computer code called "MultiDiFlux" developed in Dayananda's group enables the analysis of diffusion couples and 
modelling of multicomponent diffusion. Another field of his research is diffusion along triple junctions.

Mysore Dayananda has organised several diffusion symposia on specialised diffusion topics and coedited the proceedings [41, 42]. He also contributed a chapter on Diffusion in Ternary Alloys to the data collection Diffusion in Metals and Alloys [34] edited by Helmut Mehrer.

Professor Yongho Sohn is professor in the Department of Materials Science and Engineering at the University of Central Florida, Orlando, USA. He got his $\mathrm{PhD}$ from Purdue University (West Lafayette, Indiana) in the group of Mysore Dayananda.

His research includes microstructural analysis, multicomponent interdiffusion in multiphase alloys, powder processing, thermal barrier coatings and metallic/ceramic coatings. He is co-editor of the Journal of Phase Equilibria and Diffusion.

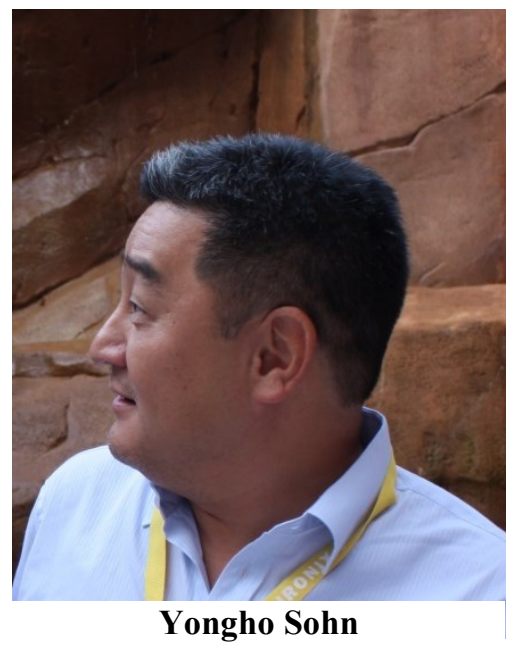

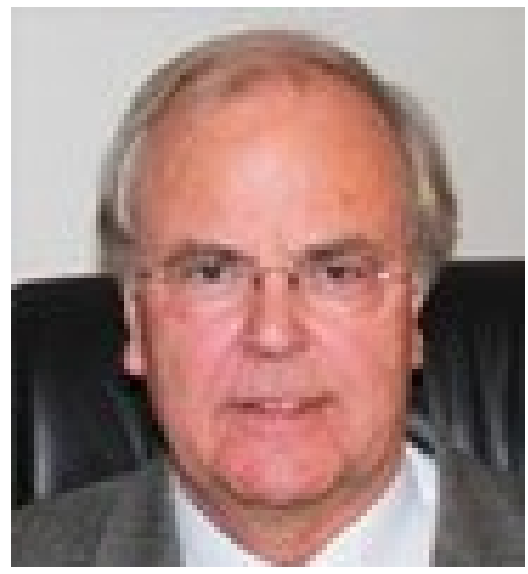

Paul Heitjans

Professor Paul Heitjans got his PhD in 1975 from the University of Heidelberg, Germany. His $\mathrm{PhD}$ thesis research focused for selfdiffusion studies of lithium by nuclear magnetic resonance (NMR) techniques. Paul Heitjans is a retired Professor of Physical Chemistry of the Leibniz University Hannover, Germany. His research interests cover questions of materials physics and physical chemistry. He applied nuclear magnetic resonance (NMR) spectroscopy, $\beta$-NMR after neutron capture, AC impedance spectroscopy, and quasi-elastic neutron scattering. Paul Heitjans is an expert for $\mathrm{Li}$ diffusion, which is important for Li-batteries. Nanocrystalline materials, ceramics, composite ma-terials, glassy and crystalline ionic conductors, $\mathrm{LiNbO}_{3}$, lithium alumosilicates, intercalation compounds, layered structures, such as $\mathrm{LiN}, \mathrm{LiXTiS}_{2}$, $\mathrm{LiC}_{6}$, intermetallic compounds (LiAl), mono-conducting polymer electrolytes, and photo-catalysts $\left(\mathrm{TiO}_{2}\right)$ were in the focus of Paul Heitjans studies.

From 1975 to 1980, Paul Heitjans was a Visiting Scientist at the Institute Laue Langevin in Grenoble from 1975 to 1980. He held Visiting Professorships at the University of Kassel, Germany (2007), at the University of Newcastle, Australia (2006) and at the University of Aix Marseille, France (2010). 


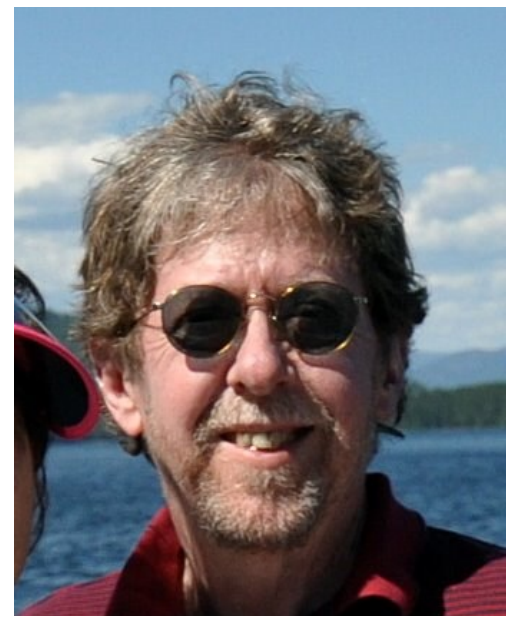

Gary Collins

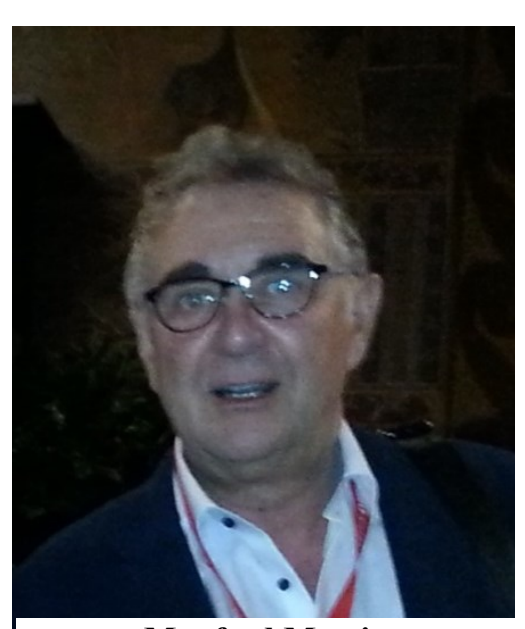

Manfred Martin

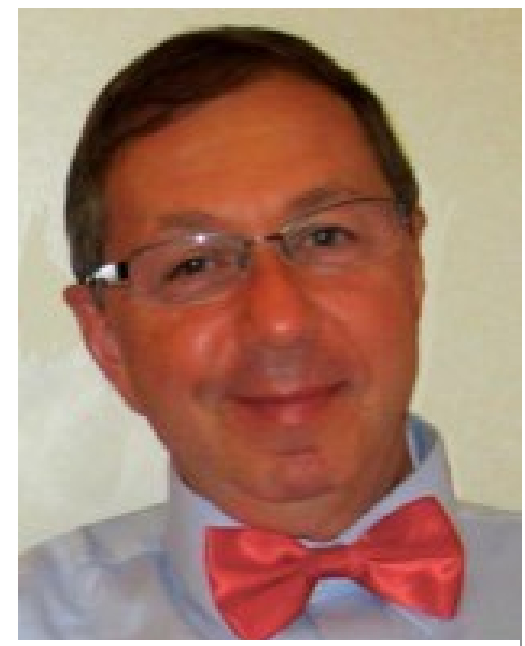

Yuri Mishin

Professor Gary Collins is Professor in Physics at the Washington State University in Pullman, Washington, USA. He got his PhD from Rutgers University, New Brunswick, USA.

Gary Collins group uses hyperfine interaction techniques to study the local structure and properties of solids. In particular, Gary Collins group applies the radioactive probe method perturbed angular correlation of gamma rays (PAC). Their studies focus on point defects and defect interactions, as well as lattice location of solutes in intermetallic compounds. They also study diffusion by measuring jump frequencies of radioactive probe atoms. PAC probes are used as tracers to study diffusion in intermetallic compounds. In 2021 Gary Collins spent several months as Visiting Scientist with the diffusion group of the University of Münster, Germany.

Professor Manfred Martin got his PhD in 1984 from the University of Hannover, Germany. He is professor in physical chemistry of solids at the RWTH Aachen, Germany. Manfred Martin is an expert for diffusion in oxides. Oxides play a role as advanced functional materials. Examples are tarnishing layers during high temperature oxidation, oxygen ion conducting oxides in high temperature fuel cells, mixed conducting oxides in oxygen permeation membranes, lithium-oxides for batteries, high temperature superconductors, ferroelectrics, catalysts. The oxides that are used are complex oxides. They contain normally several cations and exist in complicated crystal structures. Basic research concerning defect chemistry, transport properties and chemical reactivity is the basis for the improvement and optimization of functional materials.

Professor Yuri Mishin got his PhD in 1985 from the Department of Physics and Chemistry, National University of Science and Technology MISIS, Moscow, Russia, He is now professor in physics at the Department of Physics and Astronomy, George Mason University, Virginia, USA.

Yuri Mishin's research focusses on theory and computer modelling of metallic materials, materials interfaces, thermodynamics and statistical mechanics of alloys, atomic diffusion and mechanical behaviour Specific research topics include: interfaces in materials, grain boundaries, interphase boundaries, solid-liquid interfaces, and surfaces. Defects and diffusion in intermetallic compounds: diffusion mechanisms, prediction of diffusion coefficients, relation to creep deformation and other high-temperature properties. Yuri co-edited conference proceedings on Diffusion Mechanisms in Crystalline Materials [43].

Yuri Mishin has also been a Visiting Scientist in the diffusion group at the University of Münster, Germany. 


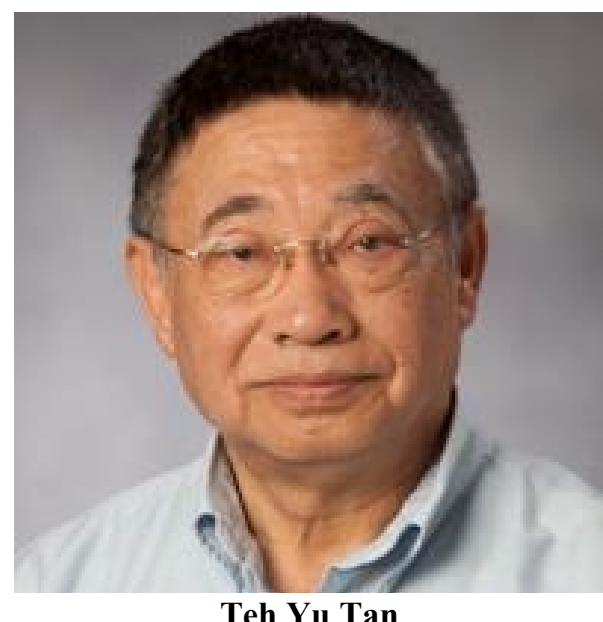

Teh Yu Tan

Professor Teh Yu Tan got his $\mathrm{PhD}$ in 1971 from the University of California in Berkeley, California, USA. He is now Professor Emeritus in the Department of Mechanical Engineering and Materials Science of the Duke University at Durham, USA, Teh Yu Tan conducted fundamental research in materials science and processes related to electronic materials. He and his colleagues have initiated the study of intrinsic gettering, which is now widely used to improve yield in integrated circuit fabrications using Czochralski silicon.

He also studied the basic aspects of precipitation, kinetic processes of defect evolution, impurity diffusion mechanisms and point defects. These studies have led to greater understanding of the structure and properties of defects in silicon. Since 1986, his research interests have also included diffusion and defect properties in III-V compound semiconducting materials.

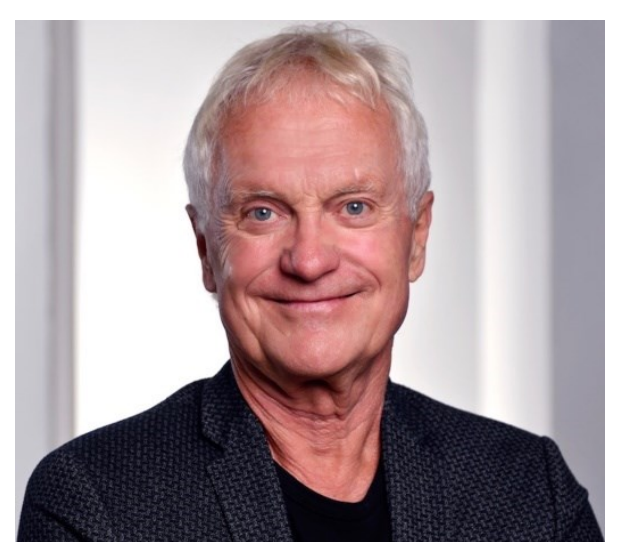

Wolfgang Jäger

Professor Wolfgang Jäger got his $\mathrm{PhD}$ in 1976 from the University of Stuttgart, Germany for his research on point defect behaviour in metals, which he performed at the Max-PlanckInstitut für Metallforschung in Stuttgart in the group of Alfred Seeger. He then spent two years as visiting scientist in Norman Peterson's group at Argonne National Laboratory, USA. In 1979 he became staff member at the Research Center Jülich, Germany. In 1996 he accepted the offer to become professor at the Christian-Albrechts-University at Kiel, Germany. As head of a Microanalysis of Materials group and Director at the Institute for Materials Science of the Faculty of Engineering, Wolfgang Jäger and his group performed microstructure research and electron microscopy of materials, applying advanced and in-situ transmission electron microscopy and nano-analytics to studies of materials and interfaces. Among others, topics were thin-film systems, interface and surface phenomena, ion implantation and defects, diffusion and defect phenomena in semiconductors, and nanomaterials. He applied in-situ transmission electron microscopy, electron diffraction methods, and nano-analytics to materials and surfaces.

Wolfgang Jäger held various positions as guest scientist and Visiting Professor at universities and laboratories, Wolfgang Jäger's research activities in the field of diffusion in solids were devoted to studies of self- and dopant diffusion and defects in III-V semiconductors. All these diffusion studies were performed in cooperation with the diffusion group at the University of Münster, Germany. Wolfgang Jäger was also interested in interdiffusion phenomena at interfaces of semiconductor layer systems and in diffusion and ordering phenomena of Si-Ge alloys. 


\section{Diffusion Scientists in Münster}

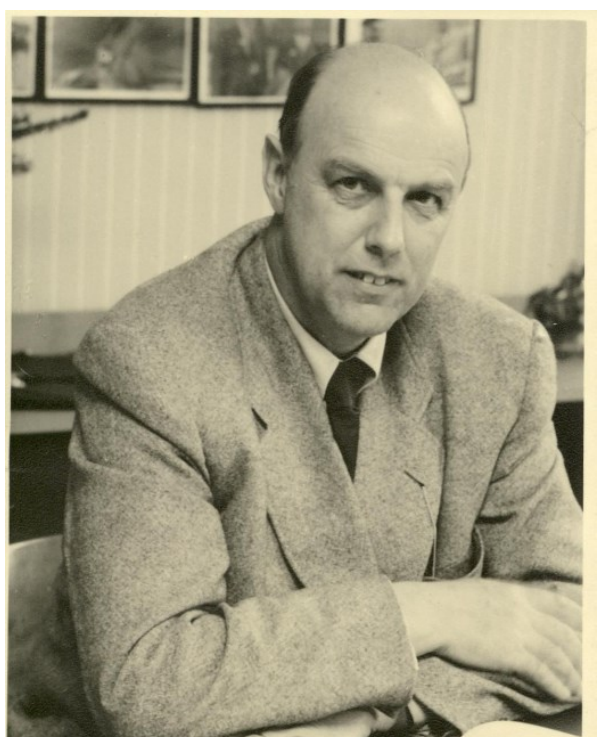

Wolfgang Seith (1900 - 1955)

Wolfgang Seith (1900 - 1955) was from 1922 to 1934 associate of Georg von Hevesy at the University of Freiburg, Germany. He then spent three years from 1934 to 1937 at the KaiserWilhelm-Institut für Metallforschung (renamed to Max-PlanckInstitut für Metallforschung) in Stuttgart. Finally he became professor in Physical Chemistry at the University of Münster from 1937 to his early death in 1955. He established diffusion research in Münster under aggravated war-time and early postwar conditions.

Seith authored a textbook on Diffu-sion in Metallen [36], which appeared in 1939. A revised version of this book appeared in 1955 and was co-authored by Seith's associate Theodor Heumann [37].

In 1954 Georg von Hevesy gave a plenary lecture at the University of Münster, when the new post-war building of the Institute for Physical Chemistry in the Chemistry Department of the university was opened

Theodor Heumann (1914 - 2002) studied physics and chemistry at the University of Göttingen, Germany. He became an associate of Seith in Münster and then professor and director of the Institut für Metallforschung of the University of Münster from 1958 to his retirement in 1982. Heumann continued research in diffusion and also studied corrosion. He installed an electron microprobe and a radiotracer laboratory for diffusion studies together with his associate Christian Herzig.

As professor emeritus, Theodor Heumann published a book with the title Diffusion in Metallen [38], to which Helmut Mehrer also contributed a chapter. A Japanese translation of Heumann's book by Fujikawa appeared in 2006.

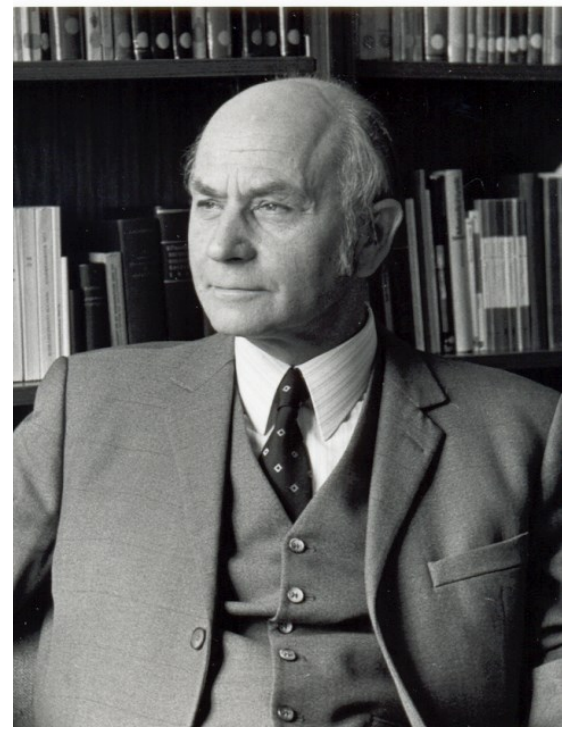

Theodor Heumann (1914 - 2002)

One author of the present paper, Professor Helmut Mehrer, got his habilitation in the group of Seeger at the university of Stuttgart, Germany, with a thesis about correlation effects in diffusion in 1974. Then he was the head of a diffusion group at the University of Stuttgart, He was appointed to be successor for the chair of Heumann in 1984 at the university of Münster. He served as full professor and director until his retirement in 2005. The institute was renamed into Institut für Materialphysik, in accordance with the wider spectrum of materials in focus.

Helmut Mehrer held Visiting Professorships at CALTECH in Pasadena, USA (1990), in Debrecen, Hungary (1993), in Osaka, Japan (2008), in Newcastle, Australia (2010), and in

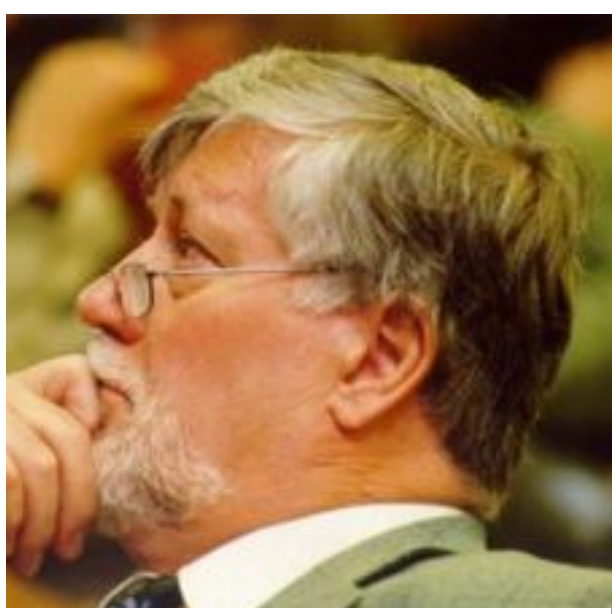

Helmut Mehrer Graz, Austria (2012). 
Diffusion was the major research topic of his laboratory at the Institut of Materialphysik. In addition to metals, further classes of materials such as elemental and compound semiconductors, intermetallic compounds, quasi-crystals, amorphous alloys, ion-conducting glasses and polymers were investigated. Sputter sectioning, spreading resistance profiling, diffusion under high pressure, measurements of ionic conduction by impedance spectroscopy were established as additional experimental tools. Ionic conduction in solids is closely related to diffusion of ions in solids. SIMS profiling was used in cooperation with other groups. Lattice- and grain-boundary diffusion was studied by radiotracer techniques using mechanical sectioning (by microtome and grinder) and sputter sectioning techniques. A data collection on Diffusion in Metals and Alloys was edited in 1990 [34]. An international diffusion conference DIMAT-96 was organized by the Münster group at Nordkirchen near Münster in 1996 and the conference proceedings were edited [39]. A textbook on Diffusion in Solids [26] was finished in 2007. Russian, Chinese and Japanese translations are available.

Most of these activities were only feasible due to cooperation with his associates Christian Herzig, Nico Stolwijk, Hartmut Bracht, and Sergiy Divinski. Their major scientific interests are mentioned in what follows.

Professor Christian Herzig got his $\mathrm{PhD}$ in Heumann's group. The scientific focus of Christian Herzig and his students was mainly devoted to studies of grain-boundary self-diffusion and grainboundary solute diffusion in metals. He performed a series of stateof-the-art measurements of grain-boundary diffusion on well characterized bi-crystals. In addition, from a comparison of solutediffusion and self-diffusion the segregation of solutes into grainboundaries was deduced. Christian was also involved in bulk and grain-boundary diffusion studies of intermetallic compounds.

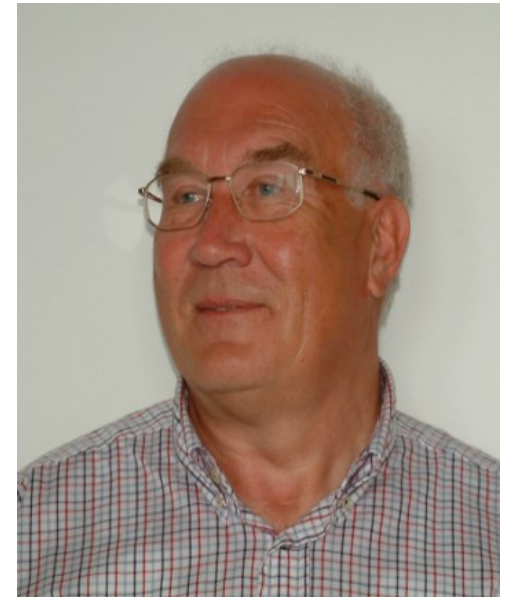

Christian Herzig (1939 - 2013)

Professor Nico Stolwijk graduated in physics at the University of Amsterdam, The Netherlands. In his PhD-work he studied diffusion in intermetallic compounds. He joined the author's group in Stuttgart as Humboldt fellow and followed him to Münster to a permanent scientist position.

Nico Stolwijk studied many diffusion processes in elemental and compound semi-conductors. He was also interested in diffusion in polymer electrolytes. The semiconductor studies included selfdiffusion, dopant diffusion, diffusion of interstitials like carbon, and diffusion of hybrid foreign elements. Hybrid elements are solutes which dissolve mainly substitutional but diffuse as interstitials. Examples are among others $\mathrm{Au}$ and $\mathrm{Zn}$ diffusion in silicon. Numerical modelling of diffusion processes was developed and applied for a better understanding of diffusion of

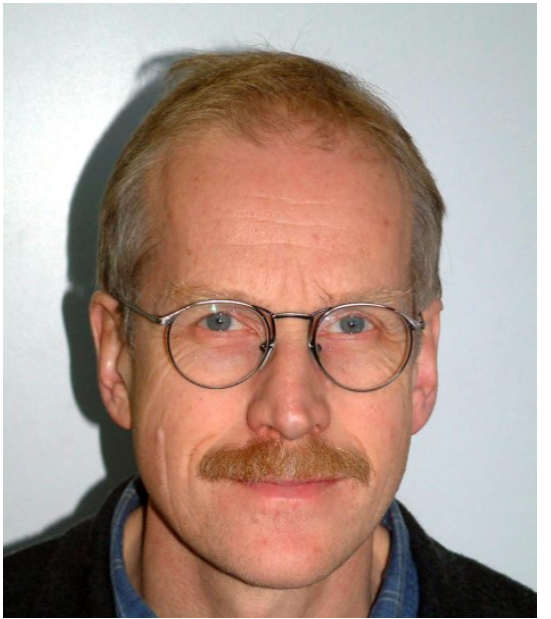

Nico Stolwijk (1950 - 2017) hybrid solutes.

Together with Hartmut Bracht and Sergiy Divinski, Nico Stolwijk organised in 2014 the international diffusion conference DIMAT 2014 at the University of Münster. They also edited the proceedings [45]. Nico Stolwijk and Hartmut Bracht contributed a chapter on Diffusion in Semiconductors to the data collection Diffusion in Semiconductors and Non-metallic Solids edited by Deszoe Beke [35]. 
Professor Hartmut Bracht got his $\mathrm{PhD}$ in close cooperation with Nico Stolwijk in Münster. He was involved in topics mentioned already above such as diffusion of hybrid solutes and numerical modelling of their diffusion properties.

In the meantime his interest shifted to related topics. These include structural investigations on amorphous semiconductors in the electron microscope, atomic and heat transport properties of isotopic modulated amorphous silicon and germanium layer structures, self- and dopant diffusion in proton irradiated silicon and germanium, and self- and dopant diffusion in nano-structured semiconductors. Hartmut Bracht was together with Nico Stolwijk co-author of a chapter of the data collection Diffusion in Semiconductors and Non-metallic Solids edited by Deszoe Beke [35].

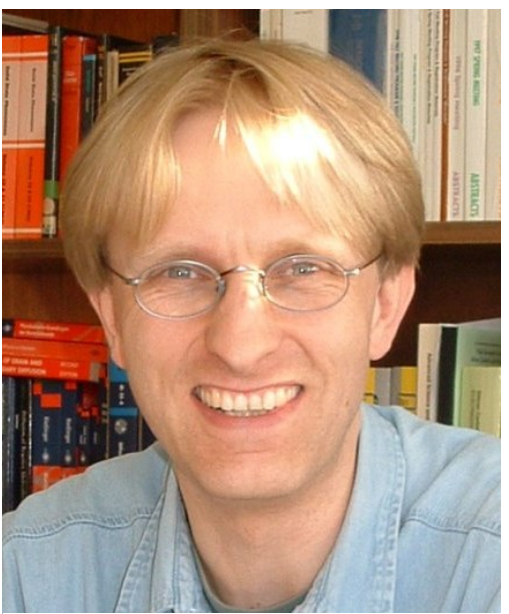

Hartmut Bracht

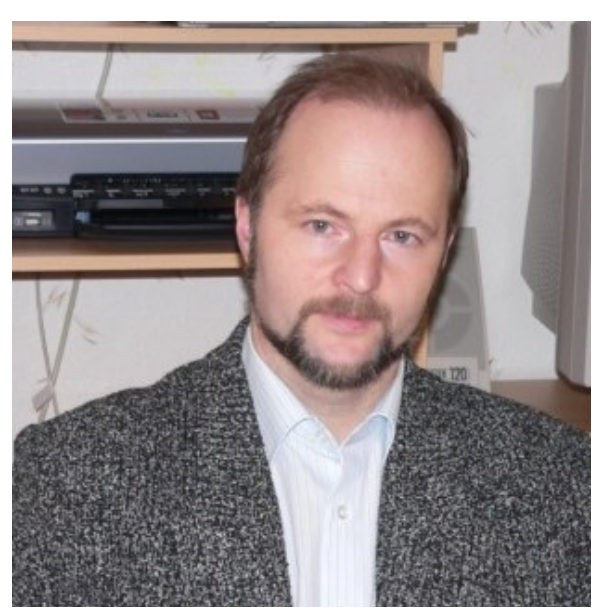

Sergiy Divinski

PD Sergiy Divinski was born and educated in the Ukraine. He joined the diffusion group in Münster as Humboldt fellow and is now one of its permanent scientific members. Sergiy Divinski was and still is involved in grain-boundary diffusion studies. More recently his focus shifted to diffusion in nanomaterials and in high-entropy alloys. Nanomaterials have a high density of grain-boundaries. The composition and the attractive properties of high-entropy alloys have stimulated Sergiy Divinski's research interest.

Sergiy Divinski was co-author of a textbook with the title Thermodynamics, Diffusion and the Kirkendall Effect in Solids [40]. He became recently one of the editors-in-chief of the journal Defect and Diffusion Forum.

\section{Textbooks and Data Collections on Diffusion In Solids}

Wilhelm Jost (1903 - 1988) was professor of physical chemistry at the University of Göttingen, Germany. He had a profound knowledge of diffusion not only for solids but also for liquids and gases. His textbook Diffusion in Solids, Liquids and Gases [39] is still a useful source of information. Jost was one of the few people who overlooked the whole field of diffusion, irrespective whether diffusion in condensed matter or in gases is concerned.

Paul Shewmon (born 1930) was professor in the Department of Materials Science and Engineering at the Ohio State University. Prior to becoming professor, he served among other positions as director of the Materials Science Division at the Argonne National Laboratory. He has written a beautiful textbook on Diffusion in Solids. It appeared for the first time in 1963 and in revised form in 1989 [31].

Jean Philibert, a retired professor of the University Paris-Sud, France, wrote a comprehensive textbook with the title Atom Movement - Diffusion and Mass Transport in Solids [32]. David Lazarus, professor at the University of Illinois, wrote in the preface to Philibert's book: "This book is a work of love by a scientist who understands the field thoroughly and deeply, from its fundamental atomistic aspects to the most practical of its 'real-world' applications". The first author of the present paper often also consulted Philibert's book.

Theodor Heumann published in 1992 a book with the title Diffusion in Metallen [38], to which Helmut Mehrer also contributed a chapter. 
The first author of the present paper, Helmut Mehrer, retired professor at the Institut für Materialphysik of the University of Münster, Germany, edited in 1990 a data collection with the title Diffusion in Metals and Alloys [34]. In 2007, two years after his retirement, he published a textbook with the title Diffusion in Solids - Fundamentals, Methods, Materials, Diffusion-controlled Processes [26].

Deszoe Beke, professor emeritus at the Institute for Solid State Physics at the University of Debrecen, Hungary, edited in 1998 a data collection with the title Diffusion in Semiconductors and Non-metallic Solids [35]. Nico Stolwijk and Hasrtmut Bracht contributed a chapter Diffusion in Semiconductors to Beke's data collection

Aloke Paul, professor at the Department of Materials Engineering, IISc Bangalore, India and Sergiy Divinski, University of Münster, Germany, published in 2014 a textbook with the title Thermodynamics, Diffusion and the Kirkendall Effect in Solids [40] together with two further coauthors T. Laurila and V. Vuorinen from Aalto University, Finnland.

John Agren, professor emeritus of the Royal Institute of Technology (KTH)/, Stockholm, Sweden, developed a tool for simulation of diffusional trans-formations in multicomponent alloys called DICTRA. The simulations are based on multicomponent diffusion and thermodynamic data, both obtained by analysing and assessing experimental information [44].

\section{Acknowledgements}

The authors are grateful to Prof. Hartmut Bracht to PD Dr. Sergiy Divinski both from the Institut für Materialphysik, Universität Münster (Germany) and to Prof. Wolfgang Jäger, Universität Kiel (Germany) for helpful comments to this manuscript.

\section{References}

[1] T. Graham, Quaterly Journal of Science, Literature an Art 27, 74 (1829).

[2] T. Graham, Philos. Mag. 2, 175, 222, 351 (1933).

[3] T. Graham, Philos. Trans. of the Roy. Soc. of London 140, 1 (1850).

[4] A. E. Fick, Annalen der Physik und Chemie 94, 59 (1855).

[5] A. E. Fick, Philos. Mag. 10, 30 (1855).

[6] W. C. Roberts-Austen, Phil. Trans. Roy. Soc. A 187, 383 (1896).

[7] J. Groh, G. von Hevesy, Annalen der Physik 63, 85 (1920).

[8] J. Groh, G. von Hevesy, Annalen der Physik 65, 216 (1921).

[9] R. Brown, Edin. J. Science 1,314 (1829).

[10] S. Dushman and I. Langmuir, Phys. Rev. 20, 113 (1922).

[11] A. Einstein, Annalen der Physik 17, 549 (1905).

[12] M. Smoluchowski, Annalen der Physik 21, 756 (1906).

[13] A. Einstein, Naturwissenschaften 50, 107 (1917).

[14] J. Perrin, C. R. Acad. Sci. Paris 147, 475 (1908).

[15] J. Perrin, C. R. Acad. Sci. Paris 147, 530 (1908).

[16] J. Perrin, Ann. De Chim.et de Phys. 18, 1 (1909).

[17] J.L. Frenkel, Z. Physik 35, 652 (1926).

[18] E.O. Kirkendall, L.Thomassen, C. Upthegrove, Trans. AIME 133, 186 (1939). 
[19] E. O. Kirkendall, Trans. AIME 147, 104 (1942).

[20] A. D. Smigelkas, E.O. Kirkendall, Trans. AIME 171, 130 (1947).

[21] L. Boltzmann, Wiedemanns Ann. Phys. 53, 959 (1894).

[22] C. Matano, Japan J. Phys. 8, 109 (1933).

[23] R. S. Barnes, Nature 166, 1032 (1950).

[24] J. C. Fisher, J. Appl. Phys. 22, 74 (1951).

[25] R. E. Hoffman, D. Turnbull, J. Appl. Phys, 22, 634 (1851).

[26] H. Mehrer, Diffusion in Solids, Fundamentals, Methods, Materials, Diffusion-controlled Processes, Springer Series in Solid State Sciences 155 (2007).

[27] J. Bardeen, C. Herring, in: Atom Movements, ASM, Cleveland, p.87 (1951).

[28] J. R. Manning, Diffusion Kinetics of Atoms in Crystals, van Norstrand Comp. 1968.

[29] A. B. Lidiard, Philos. Mag. 40, 1218 (1955).

[39] W. Jost, Diffusion in Solids, Liquids and Gases; Academic Press, New York, 1952.

[31] P. G. Shewmon, Diffusion in Solids, $2^{\text {nd }}$ edition, The Minerals, Metals \& Materials Society; Warrendale, USA, 1989.

[32] J. Philibert, Atom Movements - Diffusion and Mass Transport in Solids, Les Editions de Physique, Les Ulis, Cedex A, France, 1991.

[33] A. R. Allnatt and A. B. Lidiard, Atomic Transport in Solids, Cambridge University Press, 1991.

[34] H. Mehrer (Vol. Ed.), Diffusion in Metals and Alloys. Landolt-Börnstein, New Series, Group III: Crystal and Solid State Physics, Vol. 26, Springer Verlag, 1990.

[35] D. L. Beke (Vol. Ed.), Diffusion in Semiconductors and Non-metallic Solids, Landolt-Börnstein, New Series, Group III: Crystal and Solid State Physics, Vol.33, Springer-Verlag, 1998.

[36] W. Seith, Diffusion in Metallen, Springer-Verlag, 1939.

[37] W. Seith, Th. Heumann, Diffusion in Metallen, Springer-Verlag, 1955.

[38] Th. Heumann, Diffusion in Metallen, Springer-Verlag 1992.

[39] H. Mehrer, Chr. Herzig, N.A. Stolwijk, H. Bracht (Eds.), Diffusion in Materials, Proc. International Conference on Diffusion in Materials (DIMAT 1996), Nordkirchen, Germany, Defect and Diffusion Forum 363 Scitec Publi-cations, Zürich-Uetikon, 1997: also Defect and Diffusion Forum 143 -147, 1997.

[40] A. Paul, T. Laurila, V. Vuorinen, S.V. Divinski, Thermodynamics, Diffusion and the Kirkendall Effect in Solids, Springer Int. Publ. Switzerland, 2014.

[41] D. Gupta, A. D. Romig, M. A. Dayananda (Eds.), Diffusion in High-Technolgy Materials, Trans Tech Publications, Switzerland, 1988.

[42] A. D. Romig, M. A. Dayananda (Eds.), Diffusion Analysis and Applications, The Minerals, Metals and Materials Society, Warrendale, Pennsylvania, 1989.

[43] Y. Mishin, G. Vogl, N. Cowern, R. Catlow (Eds.), Diffusion Mechanisms in Crystalline Materials, Vol. 527, MRS Proceedings, 2014.

[44] A. Borgenstam, A. Engstrom, L. Hoglund, J. Agren, J. of Phase Equilibria 21, 269 (2000).

[45] S.V. Divinski, H. Bracht. N.A. Stolwijk (Eds.), Diffusion in Materials, Proc. International Conference on Diffusion in Materials (DIMAT 2014), August 17-22, 2014, Münster, Germany, Defect and Diffusion Forum 363 1-230, (2015). 